\title{
Observations of the Internal Tide in Monterey Canyon
}

\author{
Emil T. Petruncio,* Leslie K. Rosenfeld, and Jeffrey D. Paduan \\ Department of Oceanography, Naval Postgraduate School, Monterey, California
}

(Manuscript received 19 May 1997, in final form 8 December 1997)

\begin{abstract}
Data from two shipboard experiments in 1994, designed to observe the semidiurnal internal tide in Monterey Canyon, reveal semidiurnal currents of about $20 \mathrm{~cm} \mathrm{~s}^{-1}$, which is an order of magnitude larger than the estimated barotropic tidal currents. The kinetic and potential energy (evidenced by isopycnal displacements of about 50 $\mathrm{m}$ ) was greatest along paths following the characteristics calculated from linear theory. These energy ray paths are oriented nearly parallel to the canyon floor and may originate from large bathymetric features beyond the mouth of Monterey Bay. Energy propagated shoreward during the April experiment (ITEX1), whereas a standing wave, that is, an internal seiche, was observed in October (ITEX2). The difference is attributed to changes in stratification between the two experiments. Higher energy levels were present during ITEX1, which took place near the spring phase of the fortnightly (14.8 days) cycle in sea level, while ITEX2 occurred close to the neap phase. Further evidence of phase-locking between the surface and internal tides comes from monthlong current and temperature records obtained near the canyon head in 1991. The measured ratio of kinetic to potential energy during both ITEX1 and ITEX2 was only half that predicted by linear theory for freely propagating internal waves, probably a result of the constraining effects of topography. Internal tidal energy dissipation rate estimates for ITEX1 range from $1.3 \times 10^{-4}$ to $2.3 \times 10^{-3} \mathrm{~W} \mathrm{~m}^{-3}$, depending on assumptions made about the effect of canyon shape on dissipation. Cross-canyon measurements made during ITEX2 reveal vertical transport of denser water from within the canyon up onto the adjacent continental shelf.
\end{abstract}

\section{Introduction}

It is well established that interaction of open ocean tides with variable topography of the continental margins results in sea level and current oscillations of considerable magnitude. Given a monthlong record from a well-maintained tide gauge, the tidal component of sea level variations can be analyzed and subsequently predicted for long stretches of the coastline with reasonable accuracy. Godin (1991) notes, however, that the distances over which tidal currents remain coherent in direction and strength may be as little as a few hundred meters in the horizontal, and only a few meters in the vertical. Internal waves of tidal frequency ("internal tides"), which can account for a significant portion of the total current variance in density-stratified coastal waters, complicate the task of tidal current analysis and prediction. In many locations, the baroclinic tidal currents are stronger than the barotropic tidal currents. Over

\footnotetext{
* Current affiliation: Naval Meteorology and Oceanography Command Headquarters, (COMNAVMETOCCOM), Stennis Space Center, Mississippi.

Corresponding author address: Dr. Leslie Rosenfeld, Code OC/ Ro, Naval Postgraduate School, 833 Dyer Rd., Rm. 328, Monterey, CA 93943.

E-mail: rosenfel@oc.nps.navy.mil
}

the continental shelf, internal tides are typically characterized by current speeds of $5-20 \mathrm{~cm} \mathrm{~s}^{-1}$ and isopycnal displacement amplitudes of 20-50 m (Huthnance 1989; Foreman 1995). In certain locations, nonlinear developments such as soliton packets and borelike surges may result in much larger current speeds and isopycnal displacements (Foreman 1995).

Huthnance (1995) notes the significant contribution of baroclinic tides to internal and near-bottom mixing, particularly in submarine canyons, and cites the need for current and temperature time series with high spatial resolution to test developing 3D models of internal tides and waves. Internal wave mixing affects sediment transport, nutrient distribution, acoustic propagation, and optical clarity. Additionally, the well-mixed waters produced by internal wave action have been observed to spread laterally along isopycnals into deeper water (Gardner 1989; Ivey and Nokes 1989). This lateral spreading has been proposed as a mechanism that might weaken stratification of the ocean interior and account for the large effective eddy diffusivities of $O\left(10^{-4} \mathrm{~m}^{2}\right.$ $\mathrm{s}^{-1}$ ) required to explain the mass and heat balances in abyssal basins (Eriksen 1985; Garrett and Gilbert 1988).

As is the case in many submarine canyons, the internal tide in "Monterey Submarine Canyon" (hereafter MSC) is very energetic. Several studies of near-bottom currents in MSC report semidiurnal and higher frequency oscillatory flow in the along-canyon direction, 

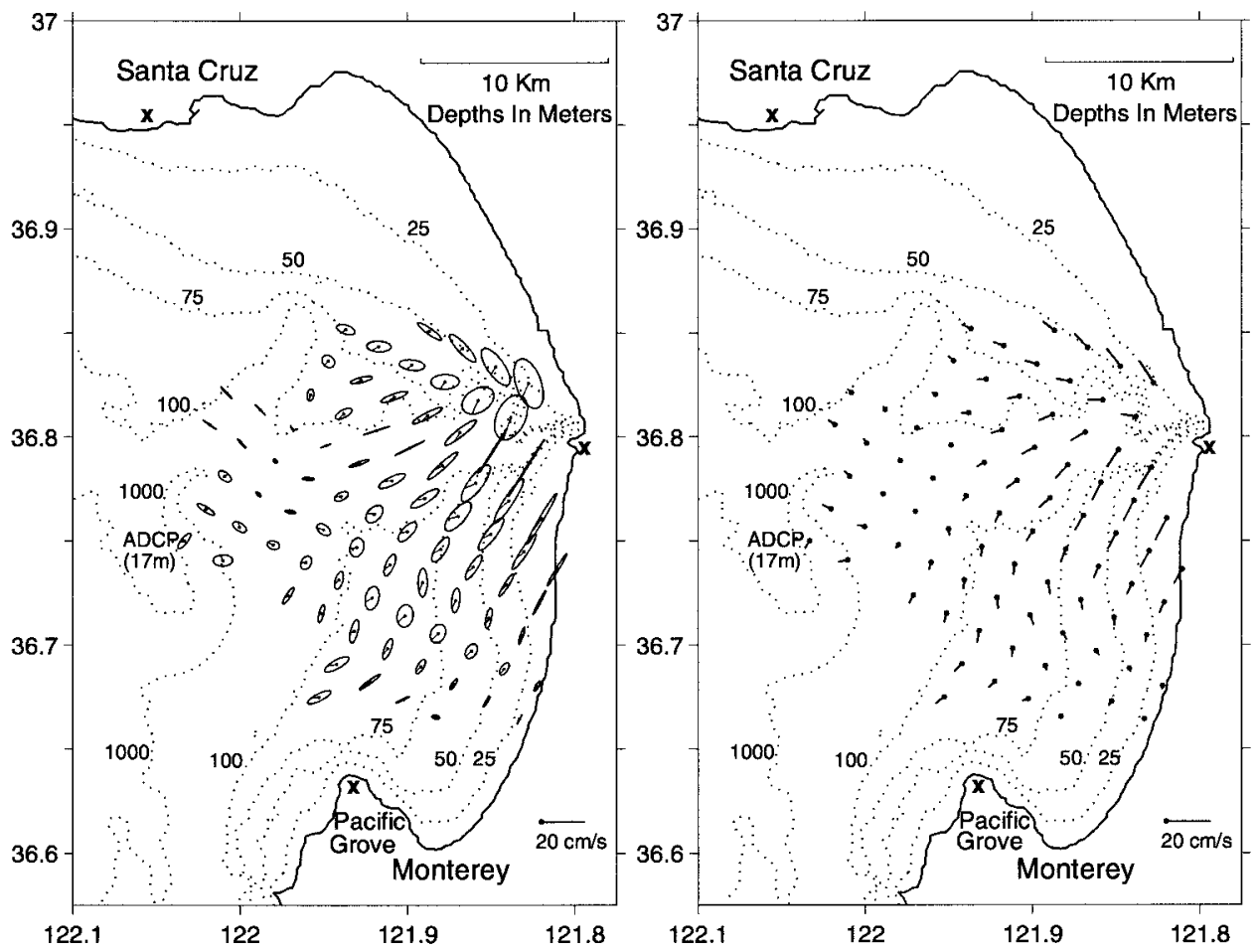

FIG. 1. The $M_{2}$ tidal current ellipses from HF radar for September 1992 (left panel) are shown with lines extending out from the center to represent the direction toward which the current flows and its speed at the time of high $M_{2}$ sea level. Current flow $3 \mathrm{~h}$ prior to high $M_{2}$ sea level (right panel) is also shown with flow directed away from the dots, which mark the centers of the HF radar bins. (See Petruncio 1993 for details.)

with borelike upcanyon surges of up to $50 \mathrm{~cm} \mathrm{~s}^{-1}$ (Gatje and Pizinger 1965; Njus 1968; Dooley 1968; Caster 1969; Hollister 1975). These measurements were made within a few kilometers of the canyon terminus or "head," near Moss Landing Harbor. In the same vicinity, near-surface current maxima of $\sim 50 \mathrm{~cm} \mathrm{~s}^{-1}$ were measured with drift poles (Lazanoff 1971) and semidiurnal isopycnal displacements of 60-120 m have been observed in depths ranging from 120 to $220 \mathrm{~m}$ (Broenkow and McKain 1972; Shea and Broenkow 1982; Heard 1992).

Recent HF-radar measurements of current flow in the top meter of Monterey Bay reveal semidiurnal currents with maximum amplitudes of $15 \mathrm{~cm} \mathrm{~s}^{-1}$ for the $M_{2}$, or principal lunar semidiurnal component, and $6 \mathrm{~cm} \mathrm{~s}^{-1}$ for the $S_{2}$, or principal solar semidiurnal component (Petruncio 1993; Paduan et al. 1995). These strong surface tidal currents appear to be directly influenced by the internal tide in the canyon, as the semidiurnal current ellipses are oriented along bathymetric contours and are amplified over the canyon head (Fig. 1). Comparison of the phases of the HF radar-derived $M_{2}$ currents and the local $M_{2}$ sea level signal shows downcanyon (offshore) flow during rising tide and upcanyon (shoreward) flow during falling tide. Towing a geomagnetic electrokinetograph near the surface above the canyon axis, McKay (1970) earlier observed this counterintuitive relationship.
Motivated by these previous findings and the apparent impact of the internal tide on the surface circulation of the bay, we undertook a field study of the internal tide in MSC. The objective was to determine the propagation characteristics (i.e., the vertical and horizontal wavelengths and phase speeds) and energy levels of the internal tide. Our measurements reveal: (i) large amplitude, bottom-intensified current and density oscillations along the canyon axis; (ii) beamlike, shoreward propagation of energy along the canyon floor in April 1994; and (iii) a standing wave in October 1994. This paper describes the field study and its results, and a subsequent paper based on Petruncio (1996) will describe numerical simulations of internal tide propagation in idealized canyon shapes.

This work is organized as follows: background information on internal wave theory and observations is presented in section 2. Sections 3 and 4 present the experiment design and results, respectively. Discussion of the results is presented in section 5 and conclusions are given in section 6 .

\section{Background on internal tides}

A comprehensive review of internal tide theory and observations is given by Wunsch (1975). A more general review of oceanic internal waves is given by Garrett and Munk (1979), while Baines (1986) and Huthnance 
(1989) focus on internal waves and tides on continental shelves. Foreman (1995), in a discussion of internal tide variability and its impact on detiding observational data, describes more recent observations.

\section{a. Linear internal wave theory}

Internal tides are generated over sloping topography, where the vertical component of the barotropic tidal current forces oscillations in the density field. If the forcing frequency (i.e., the tidal frequency) is superinertial and below the buoyancy frequency $N$, the oscillations may propagate away from the generation site as plane internal waves. In a continuously stratified medium, the energy associated with a plane internal wave travels at an angle to the horizontal determined by the radian wave frequency $\omega$, the inertial frequency $f$, and $N$. The slope $c$ of the energy flux or group velocity (the wave characteristic), derived from the dispersion relation for linear inertial-internal waves, can be expressed as

$$
c=\tan \theta=\left(\omega^{2}-f^{2}\right)^{1 / 2}\left(N^{2}-\omega^{2}\right)^{-1 / 2},
$$

where $\theta$ is the angle that the group velocity makes with the horizontal. As stratification decreases, the angle of the group velocity with respect to the horizontal steepens.

The wavevector, $\kappa=(k, m)$, which corresponds to the direction of phase propagation, is perpendicular to the group velocity. The horizontal components of the group velocity and wavevectors point in the same direction, and their vertical components point in opposite directions. By geometry then, $c$ is also equal to $m^{-1} k$ (the ratio of the horizontal to vertical components of the wavevector), and $\theta$ is also the angle that $\kappa$ makes with the vertical.

Internal wave energy incident upon bathymetry that is steeper than the wave characteristic (i.e., supercritical bathymetry) will reflect back toward deeper water with some dissipation due to near-bottom turbulent mixing. Waves incident on subcritical bathymetry will be focused into shallower water, with the wavenumber and particle velocity amplitudes increasing in inverse proportion to water depth (Wunsch 1969). Energy density increases (proportionally to the square of the ratio of reflected to incident vertical wavenumbers) and group velocity decreases (inversely with wavenumber) upon subcritical reflection (Eriksen 1982). In the case of critical reflection (i.e., where the bathymetric slope $\gamma$ is equal to $c$ ), there is a singularity in the linear solution; the energy density goes to infinity and the group velocity vanishes. It has been suggested that strong bottom intensification of the baroclinic currents and an unstable turbulent bottom boundary layer occur in this situation (Wunsch 1969). This has been confirmed by the laboratory experiments of Cacchione and Wunsch (1974) and Ivey and Nokes (1989), the numerical experiments of Slinn and Riley (1996), and the field measurements of Gilbert (1993) and White (1994). In any case, the sloping bottom is a region of significant shear, and this shear increases as the ratio of internal wave characteristic to bottom slope approaches unity.

Internal wave generation is strongest where the bottom slope is "critical" for the given wave frequency. In this situation the plane of the forcing motion, dictated by the bottom slope, and the plane of the particle motion for the free internal wave coincide. When this form of resonance exists, even very weak barotropic tidal currents can generate strong internal tides. The most obvious generation site for internal tides in the coastal ocean is at the continental shelf break, where over a distance of a few kilometers the bathymetric profile changes from supercritical $(c<\gamma)$ on the continental slope to generally subcritical $(c>\gamma)$ on the shelf.

Laboratory experiments and theoretical models indicate that near a generation site, internal tide energy is confined to beams propagating along characteristics in the cross-isobath direction. These beams can be represented by ray tracing techniques or by the superposition of numerous vertical modes that constructively interfere inside the beam and destructively interfere elsewhere. Prinsenberg et al. (1974) superpose solutions of 45 vertical modes to demonstrate internal wave generation by a long surface wave passing over an idealized continental shelf in a constant $N$ ocean and subsequent beamlike propagation of internal wave energy in the shoreward and seaward directions. The theoretical vertical thickness of the seaward moving beam, in the inviscid case, is twice the shelf break depth. Prinsenberg and Rattray (1975) show that the inclusion of vertical and horizontal eddy viscosity in the normal mode solution yields a much thicker $[O(2 \mathrm{~km})]$ oceanic beam. The shoreward beam is narrower and travels along a characteristic ray path that reflects between the surface and the subcritical floor of the continental shelf.

\section{b. Observations over continental shelves and slopes}

Most internal tide field measurements have been made over the continental shelf in depths of approximately $100 \mathrm{~m}$, and the majority of these reveal shoreward propagation in the lowest vertical mode (Baines 1986; Huthnance 1989). Despite numerous observations of oceanic internal waves through the years, reports of beamlike internal wave propagation in the ocean are exceedingly rare. Likely reasons for this are: (i) the narrow nature of the shoreward beam (and the typically coarse vertical resolution of current meter moorings on the continental shelf); (ii) the logistical difficulty of measuring internal waves seaward of the shelf break, where the beam should be wider; and (iii) the rapid dissipation of higher modes through bottom and surface reflections and nonlinear effects such as frictional damping, thermal diffusion, and wave breaking.

Torgrimson and Hickey (1979) report propagation of the internal tide in a beam $80 \mathrm{~m}$ thick over the continental slope and narrow shelf off Oregon. Beamlike 
propagation was inferred from measurements at four cross-shelf locations, which revealed baroclinic current maxima at depths corresponding to the location of theoretical characteristic rays reflecting between the sea surface and shelf floor. Much wider (500-2600 m thick) seaward-propagating beams have been observed beyond the continental shelf break in the Bay of Biscay by Pingree and New $(1989,1991)$ and off the west coast of Vancouver Island by Drakopolous and Marsden (1993). The remaining evidence for beamlike propagation lies in observations of strong internal tide signals at a few locations that correspond to likely characteristic ray paths for seaward-propagating energy (Regal and Wunsch 1973; Barbee et al. 1975; Petrie 1975; DeWitt et al. 1986; Konyaev et al. 1995).

\section{c. Observations in canyons}

Gordon and Marshall (1976) describe submarine canyons as internal wave "traps"; for most internal wave frequencies, energy incident from above the canyon will be reflected deeper into the canyon (toward the floor) by the supercritical walls. Hotchkiss and Wunsch (1982) note that in the case of internal waves propagating along the axis toward the canyon head, energy density should increase not only because of the depth change but also because the walls tend to converge; the energy density increase should be inversely proportional to the decrease in canyon cross-sectional area. Thus, for a finite frequency band (the band for which the floor slope is subcritical and the wall slopes are supercritical), submarine canyons may be viewed as conduits that focus and amplify internal wave energy, channeling it toward the canyon head.

In most canyons, internal tides are included in the band of internal wave frequencies that are amplified. In a study of currents within $30 \mathrm{~m}$ of the bottom in 27 different canyons (including Monterey), Shepard et al. (1979) noted that with the exception of aperiodic turbidity flows, the most energetic currents were those of tidal period. Currents attributed to internal tides regularly attained speeds of $20-30 \mathrm{~cm} \mathrm{~s}^{-1}$. Shepard et al. used simultaneous current measurements from adjacent moorings to estimate the horizontal component of phase propagation. In most cases, phase velocities were 20 $100 \mathrm{~cm} \mathrm{~s}^{-1}$ in the upcanyon direction.

Wunsch and Webb (1979) used Shepard's Hydrographer Canyon data to document a fivefold increase in the kinetic energy density (normalized by $N$ ) of the internal wave field, from a position near the canyon mouth to one well inside the canyon (a distance of approximately $30 \mathrm{~km}$ ). In a Hudson Canyon study, Hotchkiss and Wunsch (1982) used the same approach with data from four moored instrument arrays to depict a greater than sixfold increase in the normalized kinetic energy density over an axial distance of $20 \mathrm{~km}$. The energy density spectra of both the Hydrographer and Hudson Canyon studies show distinct peaks at the semi- diurnal frequency. By comparison, internal tides propagating over the continental shelf appear to dissipate over distances of 20-40 km (Brink 1988; Rosenfeld 1990).

Observations of strong internal tides have also been made in Baltimore Canyon (Hunkins 1988; Gardner 1989), Monterey Canyon (Broenkow and McKain 1972; Shea and Broenkow 1982; Heard 1992), and on the shelves adjacent to Trou-Sans-Fond (Park 1986), and Cape Point Valley (Largier 1994). These studies reveal the following attributes of internal waves in canyons: (i) internal wave energy spectra are dominated by the semidiurnal internal tide; (ii) baroclinic tides are more energetic in the canyon than on the adjacent continental slope and most energetic near the canyon head; and (iii) baroclinic tides are anisotropic, with greater kinetic energy in the along-canyon than cross-canyon direction.

Although Wunsch and Webb discuss the Hydrographer Canyon measurements in the context of rare exceptions to the canonical Garrett-Munk (1975) spectrum of deep ocean internal waves, submarine canyons should be recognized as features that traverse both the deep ocean and littoral regions. Hunkins notes that more than two dozen major canyons incise the continental shelf and slope off the east coast of the United States between Maine and Cape Hatteras. Hickey (1995) estimates that canyon mouths occupy $20 \%$ of the eastern Pacific shelf edge between Alaska and the equator, and in some locations (such as the Washington-Oregon coast) this figure is closer to $50 \%$. Amplified internal wave energy within these canyons may travel to within a few kilometers of the coast before it is dissipated or reflected from the canyon heads. Along their propagation path, these energetic internal waves can be expected to affect nutrient distribution, sediment transport, and optical clarity.

\section{d. Previous observations in MSC}

The head of MSC lies within $100 \mathrm{~m}$ of Moss Landing Harbor. Within the confines of Monterey Bay the axis of the canyon lies, with some meandering, in the crossshore direction $\left(080^{\circ}-260^{\circ} \mathrm{T}\right)$, bisecting the bay (Fig. 2). Between the mouth of the bay and the canyon head, a distance of approximately $20 \mathrm{~km}$, the floor of the canyon rises from $1000 \mathrm{~m}$ to $100 \mathrm{~m}$ with a slope that varies between 0.030 and $0.045\left(1.7^{\circ}-2.6^{\circ}\right)$. Over the same distance, canyon width (defined as the distance between the $150-\mathrm{m}$ isobaths on the canyon rims) decreases from approximately $11 \mathrm{~km}$ to nearly $2 \mathrm{~km}$.

In addition to the current studies mentioned in the introduction are those made by Shepard et al. (1970). They analyzed 3-4-day records of currents measured 3 and $30 \mathrm{~m}$ above the canyon axis at depths ranging from 155 to $1445 \mathrm{~m}$, and found current oscillations with average cycle lengths of $8-9 \mathrm{~h}$. These current records may have been dominated by harmonics, or overtides, rather than by the semidiurnal internal tide. By visually com- 


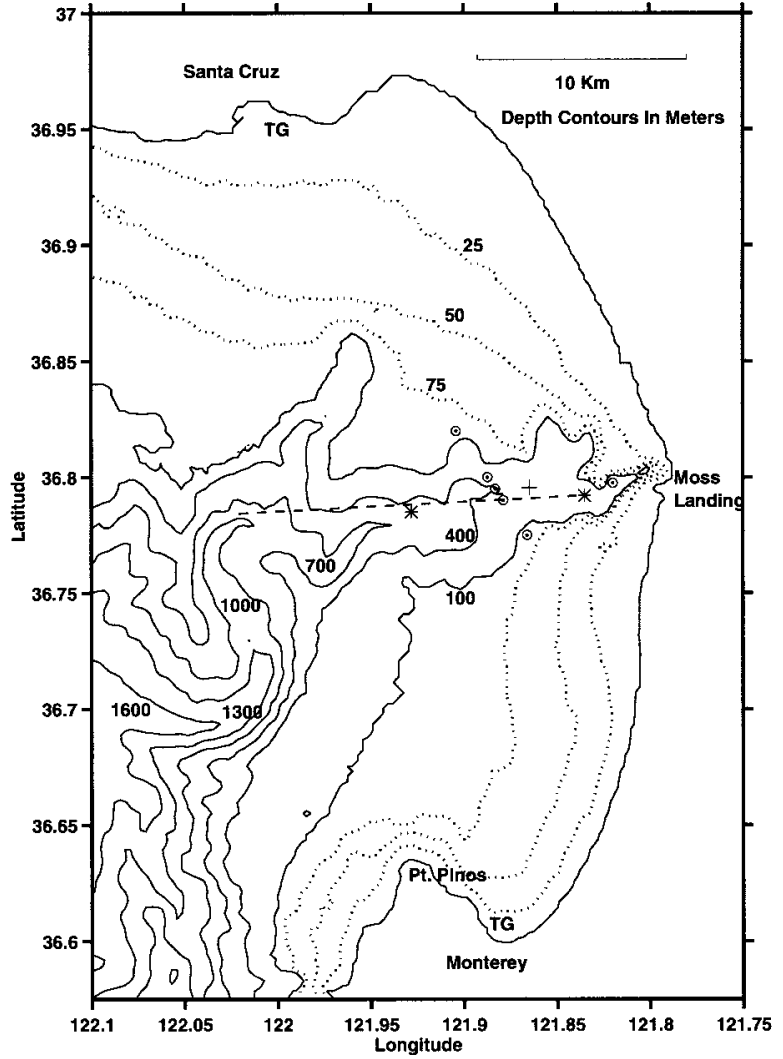

FIG. 2. Monterey Bay bathymetry and ITEX data sources. Symbols denote CTD stations for ITEX1 $(*)$ and ITEX2 $(\odot)$, the S4 mooring $(+)$, and tide gauges (TG). The dashed line shows the ITEX1 XBT track, and bathymetric contours are shown as dotted and solid lines.

paring velocity plots from three axial moorings at depths of $384 \mathrm{~m}, 357 \mathrm{~m}$, and $155 \mathrm{~m}$, Shepard et al. estimated upcanyon phase speeds of $30-45 \mathrm{~cm} \mathrm{~s}^{-1}$. Additionally, they report downcanyon propagation at $265 \mathrm{~cm} \mathrm{~s}^{-1}$ between 1061 and $1445 \mathrm{~m}$. This would be consistent with generation of internal tides in the main body of the canyon; however, the $265 \mathrm{~cm} \mathrm{~s}^{-1}$ downcanyon phase speed is questionable due to its unusually high magnitude. It is conceivable that the internal waves measured at the two deeper stations have different sources, as the canyon axis meanders significantly at the mouth of the bay.

Broenkow and McKain (1972) were the first to systematically observe tidal-band density oscillations throughout the water column in MSC, recording vertical profiles of temperature and salinity over a $25-\mathrm{h}$ period at axial locations $3 \mathrm{~km}$ apart in water depths of 120 and $220 \mathrm{~m}$. Their measurements reveal semidiurnal isopycnal oscillations with maximum vertical ranges of 80 and $115 \mathrm{~m}$. Based on an observed phase lag of 3-4 h between the stations, they conclude that an internal tide was propagating shoreward in the canyon at $20-30 \mathrm{~cm}$ $\mathrm{s}^{-1}$. These phase speeds imply a horizontal wavelength of $L_{x}=8.9-13.4 \mathrm{~km}$ for the semidiurnal internal tide.
Average values of buoyancy frequency in Monterey Bay, based on data from 50 CTD casts made at $36.64^{\circ} \mathrm{N}$, $122.14^{\circ} \mathrm{W}$ between November 1989 and December 1992 (Rosenfeld et al. 1994), range from $2 \times 10^{-3} \mathrm{~s}^{-1}$ at 1000 $\mathrm{m}$ to $3.5 \times 10^{-3} \mathrm{~s}^{-1}$ at $200 \mathrm{~m}$. Using these values for $N$ in (1), with $f=8.7 \times 10^{-5} \mathrm{~s}^{-1}$ (the inertial frequency at $36.75^{\circ} \mathrm{N}$ ), and $\omega=1.4 \times 10^{-4} \mathrm{~s}^{-1}$ (the $M_{2}$ frequency), the resulting characteristic slopes range from 0.055 (at $1000 \mathrm{~m}$ ) to 0.032 (at $200 \mathrm{~m}$ ). Thus, the slope of the canyon floor between the mouth of the bay and the canyon head (0.035-0.40) may be nearly critical for the $M_{2}$ frequency.

\section{Experiment design and execution}

Two field experiments were designed to determine the wavenumber, the phase and group velocities, and the potential and kinetic energy levels of the internal tide in the MSC. These "Internal Tide Experiments" were conducted in Monterey Bay on 23-24 April (ITEX1) and 29-31 October 1994 (ITEX2). Both cruises included continuous ADCP operation and repetitive CTD sampling at two axial stations over a 25 -h period. By transiting between CTD stations at a speed of $7 \mathrm{kt}$, it was possible to construct density and velocity time series with sufficient temporal resolution to reveal the semidiurnal isopycnal and current oscillations at both sites using only one research vessel. Spatial binning of the ADCP data allowed reconstruction of horizontal velocity time series, not only at the CTD stations but at several intermediate locations as well.

To place the results from these relatively brief periods of shipboard sampling into a longer time-frame context in which more tidal constituents can be resolved, we also examined yearlong sea level records from Monterey Bay. In addition, a monthlong record of near-bottom current and temperature from MSC and concurrent sea level records were analyzed, as were the sea level data obtained during the ITEX experiments.

\section{a. CTD and XBT data}

During ITEX1, the CTD stations were spaced $8.3 \mathrm{~km}$ apart, with the expectation that this distance would represent $1 / 4-1 / 2$ of an internal tide wavelength. CTD stations were occupied every 1.5-2 h. Upon completion of the ITEX1 CTD casts, the ship traveled a straight course for $16 \mathrm{~km}$ along a line that passed over the CTD stations (Fig. 2). During this transit, $27 \mathrm{XBTs}$ were launched at intervals of approximately $500 \mathrm{~m}$. The XBT data were used to produce a high spatial resolution "snapshot" of the temperature field along the canyon axis.

A similar along-canyon sampling strategy was used during ITEX2; however, the CTD stations were located closer together (5.6 km apart) and closer to shore (Fig. 3 ). The along-canyon measurements were followed by $25 \mathrm{~h}$ of cross-canyon CTD and ADCP surveys in order 

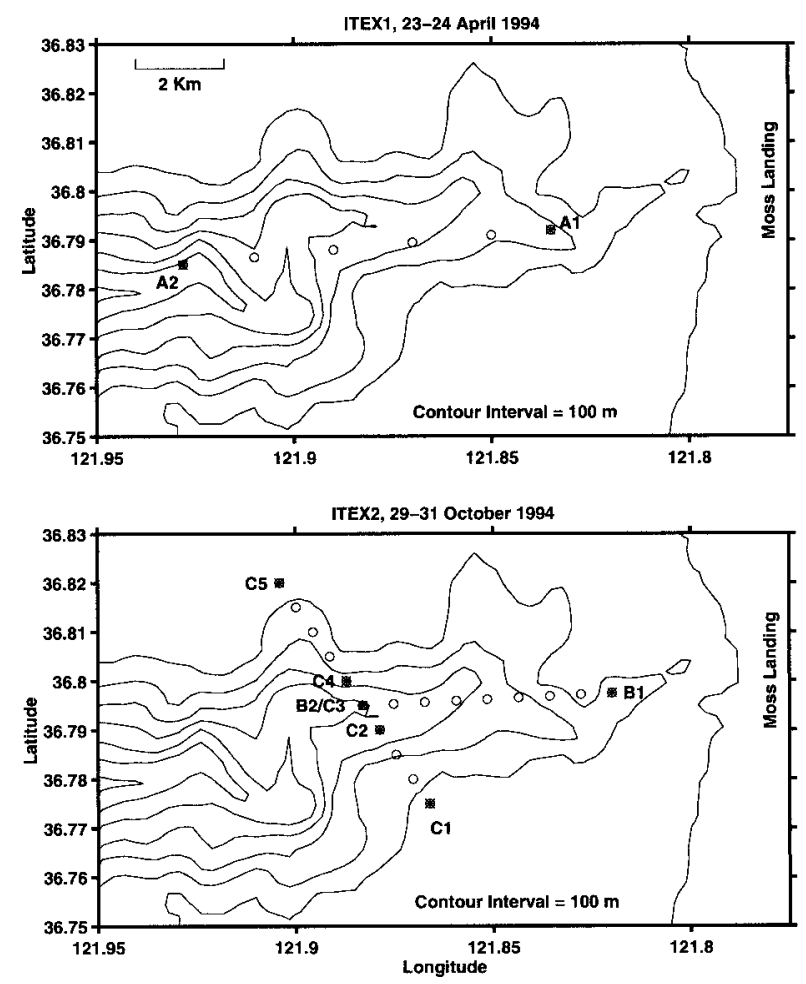

FIG. 3. CTD stations (*) and centers of VM-ADCP geographic bins $(\bigcirc)$ for ITEX1 (upper panel) and ITEX2 (lower panel).

to obtain an estimate of the internal tide energy flux through the canyon and a description of the cross-canyon structure of the internal tide. The CTD stations were positioned so that the deeper axial station was common to both the along- and cross-canyon measurements, allowing construction of a time series $50 \mathrm{~h}$ in length at that site. The remaining cross-canyon stations were located above the canyon walls and in the shallow water $(60-90 \mathrm{~m})$ on the flanks of the canyon. The orientation of the line of cross-canyon CTD stations, originally intended to be perpendicular to the along-canyon stations, was altered slightly so that the ship could head into the considerable swell.

The geographic coordinates of each CTD station, the bottom depth, and the maximum depths of the density and horizontal velocity time series constructed for each site are listed in Table 1. Postcruise analysis of differential GPS locations indicated that the repeated casts for any given CTD station were clustered within $200 \mathrm{~m}$ of each other.

Hydrographic data were collected using a Neil Brown Mark IIIB (Sea-Bird 9/11) CTD in ITEX1 (ITEX2). The Mark IIIB (9/11) was calibrated pre- and postcruise as described in Tisch (1990) (Rosenfeld et al. 1995). Data were processed and binned into 2-m and 1-m intervals for ITEX1 and ITEX2, respectively (Petruncio 1996).

\section{b. ADCP data collection and processing}

A $150-\mathrm{kHz}$ RD Instruments vessel-mounted ADCP with an array of four transducers oriented $30^{\circ}$ from the vertical in a Janus configuration was used. Although the ADCP is capable of measuring to depths greater than $400 \mathrm{~m}$, data within the lower $20 \%-30 \%$ of the water column cannot be used due to side lobe interference from reflections off the canyon floor and walls. The ADCP was configured to record data in 1-min ensemble averages and $8-\mathrm{m}$ vertical bins. The transducer head is located $3 \mathrm{~m}$ below the water line, and a 4-m blanking interval was used, so the first bin of data is centered at $11 \mathrm{~m}$ and represents velocities averaged over 7-15 m. Navigation data came from ADCP bottom-tracking when the ship was in water less than $600 \mathrm{~m}$ deep and from the DGPS system otherwise. An ADCP calibration run was conducted with bottom-tracking during each cruise so that the raw data could be corrected for alignment, gyro compass, and beam geometry errors in accordance with Joyce (1989). The subsequent steps in ADCP postprocessing, which involved editing data contaminated by side lobe reflections and converting the raw, relative current velocities to absolute velocities, are discussed in detail by Petruncio (1996). The accuracies of the resulting velocity measurements are estimated to be $\pm 4 \mathrm{~cm} \mathrm{~s}^{-1}$ (Heard 1992; Coelho 1994).

The velocity data were spatially averaged by assigning the measurements to evenly spaced along track geographic bins of $1.5 \mathrm{~km}$ for ITEX1 and $0.7 \mathrm{~km}$ for ITEX2

TABLE 1. ITEX1 and ITEX2 CTD station positions and depths.

\begin{tabular}{|c|c|c|c|c|c|c|c|}
\hline Station & $\begin{array}{r}\text { Lat } \\
\text { (deg }\end{array}$ & $\begin{array}{l}\text { itude } \\
\min N \text { ) }\end{array}$ & $\begin{array}{l}\text { Lon } \\
(\operatorname{deg} 1\end{array}$ & $\begin{array}{l}\text { situde } \\
\operatorname{nin} \text { W) }\end{array}$ & $\begin{array}{l}\text { Bottom depth } \\
\text { (m) }\end{array}$ & $\begin{array}{c}\text { Max CTD depth } \\
(\mathrm{m})\end{array}$ & $\begin{array}{c}\text { Max ADCP depth } \\
(\mathrm{m})\end{array}$ \\
\hline \multicolumn{8}{|c|}{ ITEX 1} \\
\hline A1 & 36 & 47.52 & 121 & 50.10 & 248 & 243 & 171 \\
\hline A2 & 36 & 47.10 & 121 & 55.68 & 640 & 555 & 387 \\
\hline \multicolumn{8}{|c|}{ ITEX 2} \\
\hline B1 & 36 & 47.85 & 121 & 49.19 & 175 & 147 & 115 \\
\hline $\mathrm{B} 2 / \mathrm{C} 3$ & 36 & 47.70 & 121 & 52.98 & 420 & 411 & 307 \\
\hline $\mathrm{C} 1$ & 36 & 46.50 & 121 & 51.96 & 75 & 67 & 59 \\
\hline $\mathrm{C} 2$ & 36 & 47.40 & 121 & 52.72 & 360 & 307 & 275 \\
\hline $\mathrm{C} 4$ & 36 & 48.00 & 121 & 53.23 & 230 & 227 & 227 \\
\hline $\mathrm{C} 5$ & 36 & 49.20 & 121 & 54.24 & 85 & 75 & 67 \\
\hline
\end{tabular}


TABLE 2. Dominant tidal constituents in sea level.

\begin{tabular}{|c|c|c|c|c|c|}
\hline \multirow[b]{2}{*}{ Constituent } & \multirow[b]{2}{*}{$\begin{array}{l}\text { Period } \\
\text { (h) }\end{array}$} & \multicolumn{2}{|c|}{ Monterey } & \multicolumn{2}{|c|}{ Santa Cruz } \\
\hline & & $\begin{array}{l}\text { Amplitude } \\
(\mathrm{cm})\end{array}$ & $\begin{array}{c}\text { Greenwich phase } \\
\text { (deg) }\end{array}$ & $\begin{array}{l}\text { Amplitude } \\
(\mathrm{cm})\end{array}$ & $\begin{array}{c}\text { Greenwich phase } \\
\text { (deg) }\end{array}$ \\
\hline$M_{2}$ & 12.42 & $48.9 \pm .1$ & $181.9 \pm .3$ & $49.5 \pm .3$ & $180.9 \pm .4$ \\
\hline$K_{1}^{2}$ & 23.93 & $36.4 \pm .1$ & $219.5 \pm .2$ & $36.0 \pm .2$ & $220.3 \pm .3$ \\
\hline$O_{1}$ & 25.82 & $22.8 \pm .1$ & $203.1 \pm .3$ & $22.8 \pm .2$ & $203.9 \pm .5$ \\
\hline$S_{2}$ & 12.00 & $13.0 \pm .1$ & $180.7 \pm .6$ & $13.1 \pm .3$ & $179.6 \pm 1.4$ \\
\hline$P_{1}$ & 24.07 & $11.5 \pm .1$ & $216.4 \pm .6$ & $11.4 \pm .2$ & $218.5 \pm .9$ \\
\hline $\mathrm{N}_{2}$ & 12.66 & $11.2 \pm .1$ & $155.9 \pm .6$ & $11.2 \pm .3$ & $154.2 \pm 1.7$ \\
\hline$Q_{1}$ & 26.87 & $4.1 \pm .1$ & $197.3 \pm 1.6$ & $4.1 \pm .2$ & $196.8 \pm 2.5$ \\
\hline$K_{2}$ & 11.97 & $3.6 \pm .1$ & $172.6 \pm 2.0$ & $3.9 \pm .3$ & $169.2 \pm 4.8$ \\
\hline
\end{tabular}

(Fig. 3). The cross-track width of these bins was no more than $0.5 \mathrm{~km}$. The 1 -min ensembles in each geographic bin were temporally averaged so that the sampling interval at each de facto ADCP station was the same as that of the CTD stations, 1.5-2 h.

\section{c. S4 current meter and thermistor}

Velocity and temperature data from an S4 current meter moored $1.5 \mathrm{~m}$ above the bottom at 370-m depth near the head of MSC $\left(36^{\circ} 47.73^{\prime} \mathrm{N}, 121^{\circ} 51.88^{\prime} \mathrm{W}\right)$ (Fig. 2) from 16 May to 21 June 1991 were made available by the Monterey Bay Aquarium Research Institute (MBARI). The instrument was set up to record data every 2 minutes for 10 minutes, then shut off for 10 minutes to conserve power. The raw data consist of $u$ and $v$ velocity components, which are 2-min averages, while the temperature is an instantaneous measurement made at the end of the 2-min averaging interval. The platinum temperature sensor has a reported resolution of $0.003^{\circ} \mathrm{C}$ and an accuracy of $\pm 0.02^{\circ} \mathrm{C}$. In order to obtain hourly values of velocity and temperature for conventional tidal analysis, the 2-min data were averaged and taken to represent data obtained with a 20min sampling rate. The 20 -min data were smoothed with three moving box car filters (one 3-point filter, followed by two 4-point filters) as recommended by Godin (1972) and Foreman (1978).

\section{Results}

This section presents density profiles, time series of isopycnal depth and currents, and along- and cross-canyon "snapshots" of the internal tide, as constructed from data obtained during both shipboard experiments and the S4 current meter and thermistor deployment. The least squares harmonic analysis programs of Foreman $(1977,1978)$ were used to determine the amplitudes and phases of the semidiurnal oscillations in sea level, isopycnal depth, density at a given depth, and current velocity.

\section{a. Tidal heights analyses}

In order to characterize the frequency content and spatial variability of the surface tide in Monterey Bay, tidal analyses were performed on 366-day (18 May 1991-18 May 1992) time series of hourly sea level from the Monterey and Santa Cruz stilling well tide gauges. Sixty-seven tidal constituents were resolved; however the eight strongest constituents (four diurnal and four semidiurnal) account for $95 \%$ of the observed variance. Following Filloux and Snyder (1979), the errors associated with the analyzed amplitudes and phases were determined by calculating the variance in the residual time series within constituent frequency bands (0.036$0.042 \mathrm{cph}$ for diurnal constituents and $0.077-0.084 \mathrm{cph}$ for semidiurnal) and then computing the propagation of this uncertainty in the subsequent amplitude and phase calculations (Petruncio 1996).

The results for Monterey and Santa Cruz show that the bay essentially co-oscillates, and is characterized by a mixed, predominantly semidiurnal tide (Table 2). The differences in amplitude for the major constituents at Monterey and Santa Cruz are within the estimated 1.5$\mathrm{cm}$ accuracy of the tide gauges (Shih and Baer 1991; Lentz 1993). The difference in phase between the two locations for the $M_{2}$ constituent is $0.3^{\circ}-1.7^{\circ}$, which indicates an arrival of the $M_{2}$ signal 1-3 min earlier in Santa Cruz than in Monterey. The phase differences for the other major constituents are either smaller than this or insignificant compared to the calculated phase errors. These small phase differences are most likely due to differences in the mechanical response of the tide gauges or the influences of bathymetry and harbor geometry in the immediate vicinity of the gauges, rather than propagation of a shallow water gravity wave in the bay, which would require about 20 min to travel from Santa Cruz to Monterey. The lack of horizontal propagation of the surface tides within the bay is to be expected, given that the width of the bay is much less than the barotropic Rossby radius of deformation (Werner 1992).

The second strongest semidiurnal constituent, $S_{2}$, has an amplitude of $13 \mathrm{~cm}, 26 \%$ as large as $M_{2}$. Thus, in a short record, attributing semidiurnal oscillations solely to the $M_{2}$ constituent is an appropriate simplification, with the understanding that the calculated amplitude and phase actually represents a band of frequencies around the $M_{2}$ consituent. Using the standard Rayleigh comparison constant of 1 , a record length of $355 \mathrm{~h}$ would 
be required for inclusion of both $M_{2}$ and $S_{2}$ in the least squares harmonic analysis (Foreman 1977).

\section{b. Barotropic tidal current estimate}

A theoretical model is used to estimate the barotropic tidal currents and thus separate them from the baroclinic ones (Huthnance and Baines 1982). The lack of current data in the lower $20 \%-30 \%$ of the water column, where baroclinic tidal currents are expected to be intensified due to the near-critical bottom slope, discourages use of the depth-averaged data to estimate the barotropic tidal currents.

Given that the bay co-oscillates at tidal frequencies, mass conservation can be used to calculate the strength of the barotropic tidal currents. Equating the volume flux into the bay during flood tide with the volume change between low and high tide, we estimate the temporally averaged barotropic flood current as

$$
u=\frac{\eta A}{t h w},
$$

where, for the $M_{2}$ component, $\eta=$ tidal range $(1 \mathrm{~m})$, $A=$ surface area of the bay $\left(500 \mathrm{~km}^{2}\right), t=$ duration of flood tide $(6.2 \mathrm{~h}), h=$ average depth across the bay mouth $(175 \mathrm{~m})$, and $w=$ width of the bay at the mouth, defined by a line connecting Santa Cruz and Pt. Pinos (36 km) (Fig. 2). Equation (2) yields an average semidiurnal flood current of $0.37 \mathrm{~cm} \mathrm{~s}^{-1}$, corresponding to a sinusoidally varying current with $0.58 \mathrm{~cm} \mathrm{~s}^{-1}$ amplitude. This amplitude is consistent with the weak crossshore current expected of the very long wavelength $(\approx 8000 \mathrm{~km})$ Kelvin-like wave of $M_{2}$ frequency propagating northward along the California coast, as modeled by Munk et al. (1970) and further discussed by Miles (1972). It is also in very close agreement with the Battisti and Clark (1982) estimate of $0.2-0.5 \mathrm{~cm} \mathrm{~s}^{-1}$ for the cross-shore $M_{2}$ currents over the narrow shelf off central California and the barotropic $M_{2}$ currents observed off northern California by Rosenfeld and Beardsley (1987). Breaker and Broenkow (1994) arrive at a much larger estimate $\left(18 \mathrm{~cm} \mathrm{~s}^{-1}\right)$ for the semidiurnal flood current into Monterey Bay. We consider this larger value to be in error, primarily because it is based on a shallow water wave propagating with a shoreward component without reflection. For the purposes of this study, the $\sim 1 \mathrm{~cm} \mathrm{~s}^{-1}$ barotropic $M_{2}$ current in MSC is assumed to be negligible, and the results of the tidal analyses performed on the ADCP measurements will be taken to represent the baroclinic tidal currents.

\section{c. Along-canyon observations}

\section{1) DENSITY}

Isopycnal depths were constructed from the CTD data as described by Petruncio (1996). Time series of these for the axial CTD stations, the concurrently observed sea level variations (as recorded at the Monterey tide gauge station), and the $M_{2}$ amplitudes and phases resulting from harmonic analyses of the time series are presented in Figs. 4 (ITEX1) and 5 (ITEX2). In both experiments, large amplitude $(>10 \mathrm{~m})$ internal tides are apparent throughout the water column at the shallow stations and below $100 \mathrm{~m}$ at the deep stations. The maximum $M_{2}$ displacement amplitudes are $39 \mathrm{~m}$ in ITEX1 and $35 \mathrm{~m}$ in ITEX2 (i.e., total crest-to-trough displacements of 78 and $70 \mathrm{~m}$, respectively). Due to the short record lengths, it is difficult to place "error bars" on the amplitude and phase plots. Conventional error estimate techniques (Filloux and Snyder 1979; Tee 1982) use the assumptions that the covariances of the sine and cosine terms resulting from the least squares fit are equal to zero and that their variances are equal to each other. These assumptions may not hold true for short records. As a relative measure of the confidence in the analysis, the percent variance accounted for by the $M_{2}$ fit is depicted below the time series of isopycnal depths. In lieu of a more rigorous error analysis, it will suffice to say that over those depths with $M_{2}$ amplitudes of $20 \mathrm{~m}$ or greater, the time varying signal based on the analyzed $M_{2}$ amplitudes and phases accounts for at least $50 \%$ of the variance in the observed density field.

\section{(i) Energy and phase propagation-ITEXI}

The $M_{2}$ phases in Figs. 4 and 5 are plotted in hours relative to the phase of the $M_{2}$ sea level signal. A positive value indicates the length of time that passes between high tide for the $M_{2}$ component of sea level and the cresting of an isopycnal displacement caused by the semidiurnal internal tide; since the $M_{2}$ period is $12.4 \mathrm{~h}$, a phase lag of $6.2 \mathrm{~h}$ would indicate a $180^{\circ}$ phase difference between the baroclinic and barotropic tides. The ITEX1 phases generally increase with depth, which indicates downward phase propagation of the internal tide. The phase increases nearly linearly between 125 and $400 \mathrm{~m}$ at the deep station, over which a 2.5 -h increase in phase occurs, and between 50 and $175 \mathrm{~m}$ at the shallow station where a 2 -h increase occurs. At a given depth, the phases at the shallow station lag those at the deep station, which indicates an eastward component of phase propagation.

The linear phase increase with depth in the ITEX1 measurements is indicative of beamlike behavior, and the slope of the beam can be determined by finding the depths at which a given phase value is found at both CTD stations (since phase is theoretically constant along the beam). A phase lag of $5 \mathrm{~h}$, for example, occurs at $410 \mathrm{~m}$ at the deep station and $75 \mathrm{~m}$ at the shallow station. Since the station separation is $8.3 \mathrm{~km}$, the slope of the beam is $(0.41-0.075) / 8.3=0.04$, which corresponds to an angle of $2.3^{\circ}$. The horizontal components of phase and energy propagation share a common direction, so the energy must be propagating eastward and upward from the deep station to the shallow station at an angle 

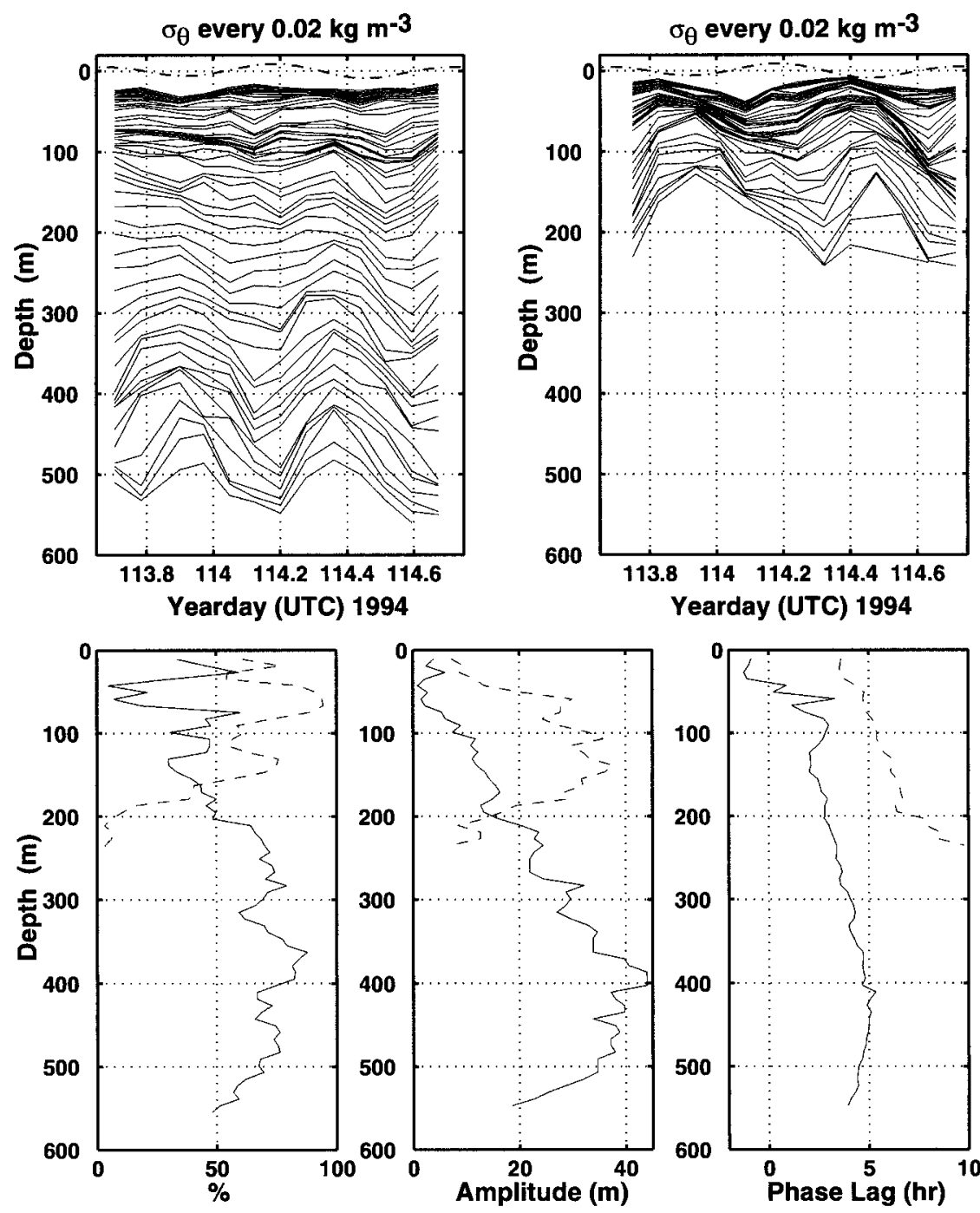

FIG. 4. Time series of isopycnal depths (solid) and sea level (dashed) during ITEX1 at the deep (upper left) and shallow (upper right) CTD stations. Sea level oscillations were demeaned and exaggerated by a factor of 10 . Percent variance described (left), amplitude (center), and phase (right) for the fit of an $M_{2}$ wave to the data are shown in the lower panels as a function of depth at the deep (solid) and shallow (dashed) stations. of about $2.3^{\circ}$, comparable to the mean slope of the canyon floor.

The wave characteristic slope can also be determined from the horizontal and vertical components of phase velocity $\left(c_{p_{x}}\right.$ and $\left.c_{p_{z}}\right)$ since $\tan \theta=m^{-1} k=c_{p_{z}} c_{p_{x}}^{-1}$. The method of least squares is used to fit a straight line to the portion of the phase plots that indicate a linear increase in phase with depth. The slope of this line $(\Delta G)^{-1} \Delta z$ is taken to be $c_{p_{z}}$ at each station: $c_{p_{x}}$ is calculated by dividing the distance between the two stations by the phase difference between stations $\left[(\Delta G)^{-1} \Delta x\right]$ at those depths over which $(\Delta G)^{-1} \Delta z$ is linear. Using this method, $c_{p_{z}}$ equals $2.7 \mathrm{~cm} \mathrm{~s}^{-1}$ downward at the deep station (vertical wavelength, $L_{z}=1.2$ $\mathrm{km})$ and $1.7 \mathrm{~cm} \mathrm{~s}^{-1}$ downward at the shallow station
$\left(L_{z}=0.76 \mathrm{~km}\right) ; c_{p_{x}}$ varies slightly over the depths of linear phase increase from $62.2 \mathrm{~cm} \mathrm{~s}^{-1}$ at $125 \mathrm{~m}$ to 57.4 $\mathrm{cm} \mathrm{s}^{-1}$ at $175 \mathrm{~m}$, with an average value of $59.6 \mathrm{~cm} \mathrm{~s}^{-1}$ $\left(L_{x}=26.65 \mathrm{~km}\right)$. Using the average value of $c_{p_{x}}$ and the values of $c_{p_{2}}$ determined at each station, $\theta=2.6^{\circ}$ at the deep station and $1.6^{\circ}$ at the shallow station. This change in propagation angle for the group velocity is consistent with the flatter trajectories expected in shallower depths, where $N$ is larger. The average of these two angles is $2.1^{\circ}$, close to the $2.3^{\circ}$ estimate obtained by comparing the depths of equal phases.

A third way to calculate the angle of propagation is to use the density profiles from each station to compute $N$ profiles and use these to solve (1). The average values of $N$, calculated over the depths of the linear phase 

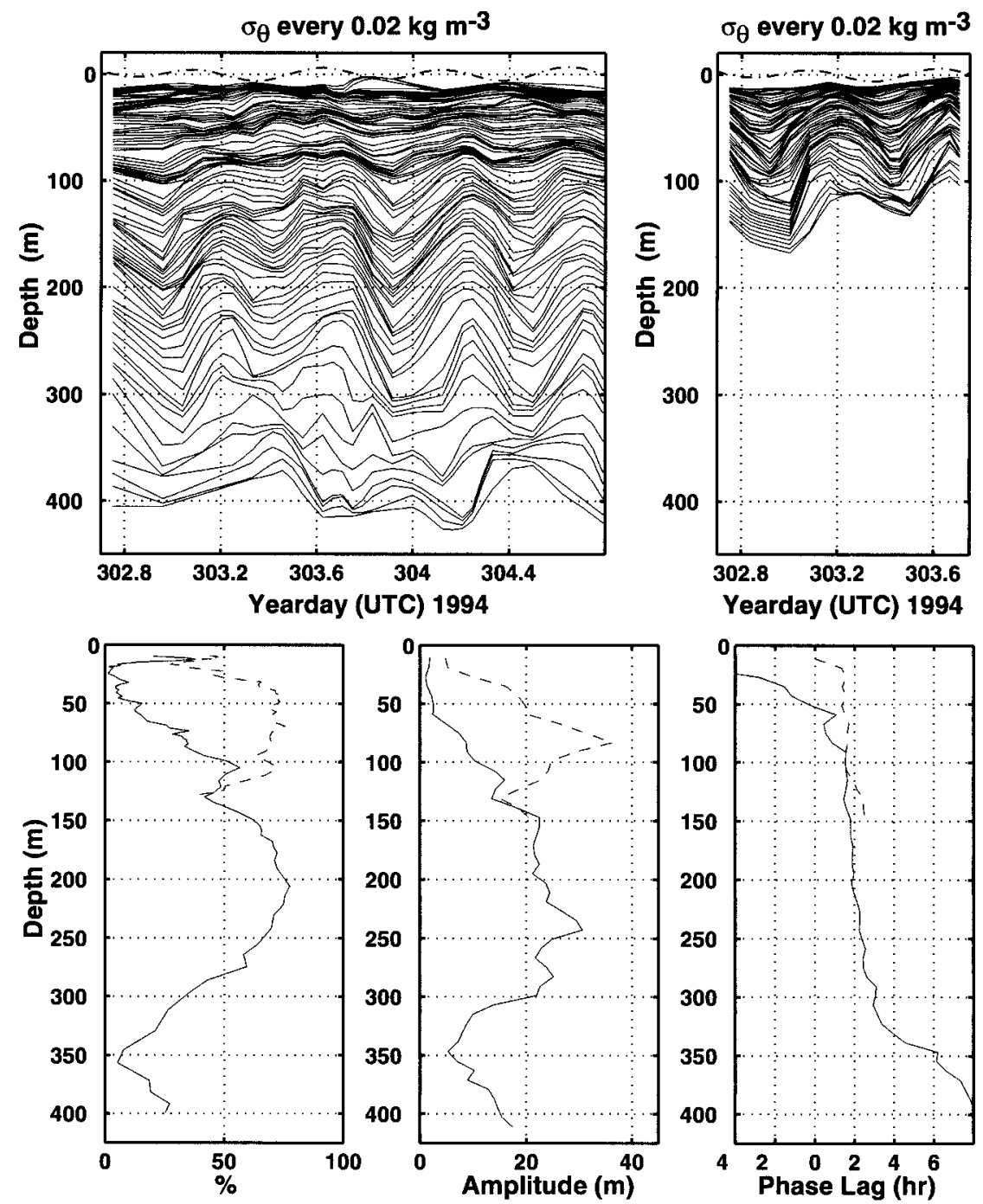

FIG. 5. As in Fig. 4 but for ITEX2. Note that a longer time series $(\sim 50 \mathrm{~h})$ was collected and used for the $M_{2}$ wave fit at the deeper station, as opposed to $\sim 25 \mathrm{~h}$ at the shallower station.

increases, are $3.63 \times 10^{-3} \mathrm{~s}^{-1}$ between 125 and $395 \mathrm{~m}$ at the deep station and $5.19 \times 10^{-3} \mathrm{~s}^{-1}$ between 50 and $180 \mathrm{~m}$ at the shallow station. Using these values, with $f=8.7 \times 10^{-5} \mathrm{~s}^{-1}$ and $\omega=1.4 \times 10^{-4} \mathrm{~s}^{-1}$, we obtain propagation angles of $1.7^{\circ}$ and $1.2^{\circ}$ at the deep and shallow stations, respectively. These are $25 \%-35 \%$ smaller than the angles computed by the other methods, but qualitatively similar in that the steeper angle to the horizontal is found at the deeper station. Better agreement with the previous estimates is obtained by setting $f$ equal to zero in (1), which then yields angles of $2.2^{\circ}$ (deep station) and $1.6^{\circ}$ (shallow station). Neglecting the effect of the earth's rotation helps to compensate for the presence of the canyon walls, the effects of which are not accounted for in the dispersion relation. This subject will be discussed further in section $4 \mathrm{c}(2)$.

The wave group velocity at the two stations can be calculated using the equation for waves in the "rotating wave regime" (Gill 1982), appropriate for waves with $\omega=O(f)$ but $\omega \geq f$ :

$$
c_{g_{x}}=\frac{N\left(\omega^{2}-f^{2}\right)^{1 / 2}}{\omega m}, \quad c_{g_{z}}=-\frac{\left(\omega^{2}-f^{2}\right)^{3 / 2}}{\omega N k_{H}} .
$$

Using the buoyancy frequencies and wavenumber components discussed above, these equations yield upcanyon group velocities of 54.9 and $49.2 \mathrm{~cm} \mathrm{~s}^{-1}$ at the deep and shallow stations, respectively. Since the particle velocity in a linear wave cannot exceed the group velocity, $55 \mathrm{~cm} \mathrm{~s}^{-1}$ may be the upper bound on current speeds associated with the internal tide in MSC, except perhaps in turbulent bores. This limit is consistent with maximum tidal current velocities of $50 \mathrm{~cm} \mathrm{~s}^{-1}$ observed in and above MSC by Dooley (1968) and McKay (1970). If rotational effects are considered negligible, these group velocities are reduced by $2 \mathrm{~cm} \mathrm{~s}^{-1}$ at the deep station and by $1 \mathrm{~cm} \mathrm{~s}^{-1}$ at the shallow station. 


\section{(ii) Energy and phase propagation-ITEX2}

Although the internal tide is of similar amplitude in ITEX1 and ITEX2, the vertical and horizontal phase variations in the two experiments are quite different. The variations in phase of the ITEX2 isopycnal displacements (Fig. 5) are indicative of a standing wave, as opposed to a progressive wave as in ITEX1. Between 90 and $250 \mathrm{~m}$ at the deep station and between 20 and $110 \mathrm{~m}$ at the shallow station, phase is nearly constant at approximately $2 \mathrm{~h}$ (relative to $M_{2}$ sea level). In the upper and lower $100 \mathrm{~m}$ of the deep station, the phase changes approximately $180^{\circ}(6 \mathrm{~h})$. The $180^{\circ}$ phase shift in the lower $100 \mathrm{~m}$ corresponds to a node in vertical displacement, which is represented by the $M_{2}$ amplitude minima at $350 \mathrm{~m}$. The $180^{\circ}$ phase shift near the surface may also coincide with a node, but the near-surface minimum in vertical displacement does not necessarily verify the presence of an internal wave node since displacements are expected to be minimal in the region of strong stratification. Further evidence of a standing wave will be presented in the discussion of the baroclinic tidal currents observed in ITEX2.

\section{2) Currents}

As in the case of the isopycnal analyses, the ADCPderived $u$ and $v$ components of velocity were linearly interpolated to hourly values and subjected to harmonic analysis. In general, the $u$ component of velocity was much stronger than the $v$ component and increased in strength with depth. Due to the meandering of the canyon axis (Fig. 2), no attempt was made to rotate the orthogonal velocity components into along- and crosscanyon directions, although in general $u$ is nearly alongcanyon. The variance of each time series of $u$ for the along-canyon measurements is depicted in the top panels in Fig. 6. The bottom panels of Fig. 6 indicate the percentage of $u$ variance accounted for by fitting an $\mathrm{M}_{2}-$ period wave to the data.

Maximum values of $u$ variance were similar in both experiments: $145 \mathrm{~cm}^{2} \mathrm{~s}^{-2}$ (ITEX1) and $141 \mathrm{~cm}^{2} \mathrm{~s}^{-2}$ (ITEX2). The variances of the $v$ component of velocity (not depicted) were generally less than $25 \mathrm{~cm}^{2} \mathrm{~s}^{-2}$ at most depths, although values as high as $56 \mathrm{~cm}^{2} \mathrm{~s}^{-2}$ (ITEX1) and $64 \mathrm{~cm}^{2} \mathrm{~s}^{-2}$ (ITEX2) were observed at a few scattered locations. Except for portions of the water column where the $u$ variance is weak $\left(<20 \mathrm{~cm}^{2} \mathrm{~s}^{-2}\right)$, the variance of the $M_{2} u$ accounts for $50 \%-90 \%$ of the total variance in $u$. This simplified presentation of the ADCP measurements demonstrates that, at those canyon locations in which strong currents were observed, most of the current activity is attributable to semidiurnal oscillations. Consistent with beamlike propagation, the depths at which the $M_{2}$ currents stand out against background noise correspond with the depths of strong $M_{2}$ isopycnal oscillations. It should be noted that some of the regions of weak current variance correspond to those portions of the ship's track that leave the canyon axis and pass over portions of the canyon walls, as is the case for the ITEX2 data just west of station B1, $4 \mathrm{~km}$ from the canyon head (Fig. 3).

The steering effect of the canyon walls can be seen in the orientation of the $M_{2}$ tidal ellipses, presented in Figs. 7 and 8. Over those bottom depths at which strong $M_{2}$ currents are found, ellipse orientation is uniform and aligned with the canyon axis. The maximum $M_{2}$ currents are approximately $20 \mathrm{~cm} \mathrm{~s}^{-1}$ in the along-canyon direction, which corresponds to an along-canyon particle excursion of $2.8 \mathrm{~km}$ before current reversal. Some rotation of the ellipse orientation occurs in the upper part of the water column, above and below the depths of the weakest $M_{2}$ currents. This rotation is likely due to vertical shear stresses (Prandle 1982). The near-surface $M_{2}$ current maxima may be due to the presence of internal tides at the base of the surface mixed layer, or to reflected beams of bottom-generated internal tide energy, discussed later. Theoretically, the ratio of the semimajor to the semiminor axis for an internal gravity wave is equal to the ratio of $\omega$ to $f$, which for the $M_{2}$ frequency and the latitude of Monterey Bay is 1.6:1. The observed ratios in the nearly rectilinear ellipses are considerably greater, most likely due to the presence of the canyon walls.

The observed $u$ velocities, the tidal fits to these observations, and the concurrent isopycnal displacements $\xi$, are plotted versus depth and time in Fig. 9 for the ITEX1 CTD stations. Between 200 and $400 \mathrm{~m}$ at the deep station and throughout the water column at the shallow station, maximum shoreward flow occurs approximately $1 / 4$ cycle $(3 \mathrm{~h})$ before the isopycnal reaches its maximum upward displacement, that is, $u$ leads $\xi$ (and $\rho^{\prime}$ ) by approximately $90^{\circ}$. As seen from the polarization equations (Gill 1982), this phase relationship is consistent with an internal wave propagating in the horizontal and vertical directions (i.e., in a beamlike manner) with $k>0$ (eastward) and $m<0$ (downward).

Since $u$ and $w$ are in phase in these circumstances, the particle motion should lie in the plane of the wave characteristic. The amplitudes of $u$ (or more appropriately, the amplitude of the ellipse semimajor axis) and $w$, which is computed from

$$
w_{o}=\xi_{o} \omega=\frac{\rho_{o}^{\prime}}{\partial \rho_{o} / \partial z} \omega,
$$

inside the beam can thus be used as another check on the previously calculated slope of the wave characteristic since $w_{o} / u_{o}=\tan \theta$. Using the depths at which $u$ leads $\rho^{\prime}$ by approximately $90^{\circ}$ as a criteria for identifying the location of the beam, the range of values for $\theta$ calculated from $\tan ^{-1}\left(w_{o} / u_{o}\right)$ is $1.83^{\circ}-2.94^{\circ}$ between 250 and $387 \mathrm{~m}$ at the deep station and $1.31^{\circ}-2.73^{\circ}$ between 51 and $171 \mathrm{~m}$ at the shallow station. These angles and depths are in reasonable agreement with the calculations based on the isopycnal phases (i.e., 2.6 and $1.6^{\circ}$ at the deep and shallow stations, respectively). 

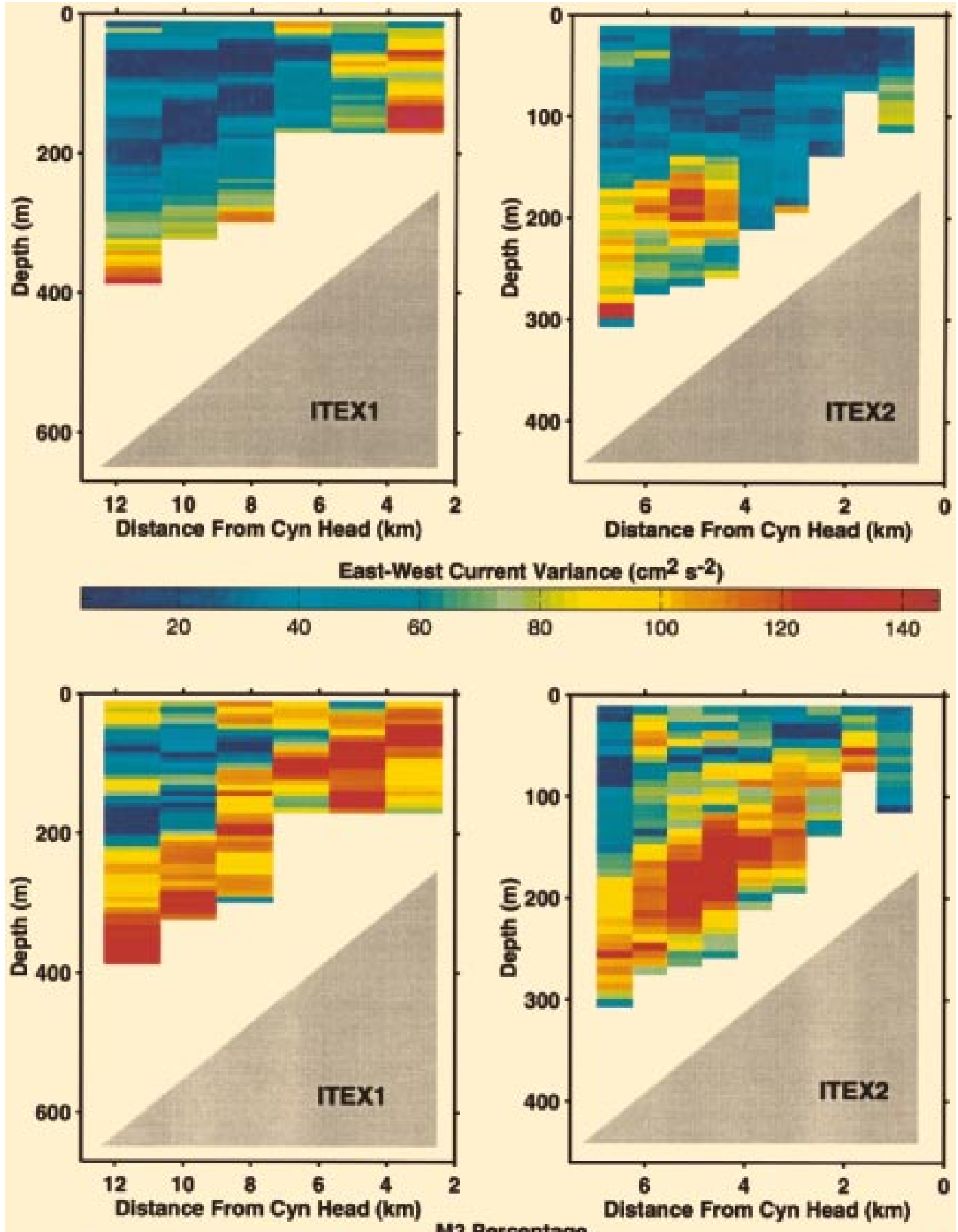

M2 Percentage

$\begin{array}{lllllllllll}0 & 10 & 20 & 30 & 40 & 50 & 60 & 70 & 80 & 90 & 100\end{array}$

FIG. 6. Variance of the east-west velocity (upper panels) and the percent variance accounted for by the $M_{2}$ wave fit (lower panels), computed every $8 \mathrm{~m}$ in depth from along-canyon ADCP measurements, during ITEX1 (left) and ITEX2 (right). The wedge in each panel represents the approximate depth and slope of the canyon floor. 

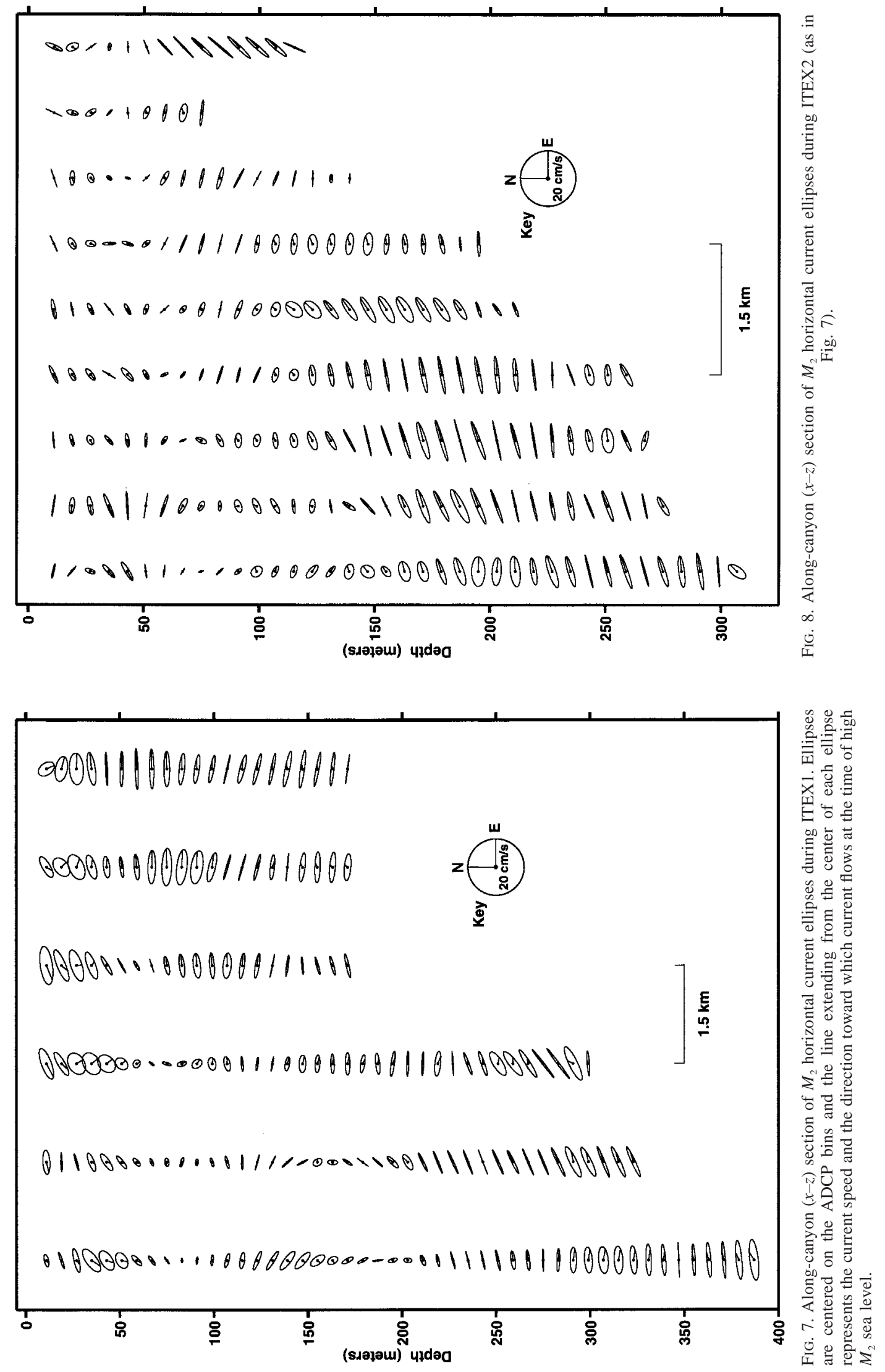

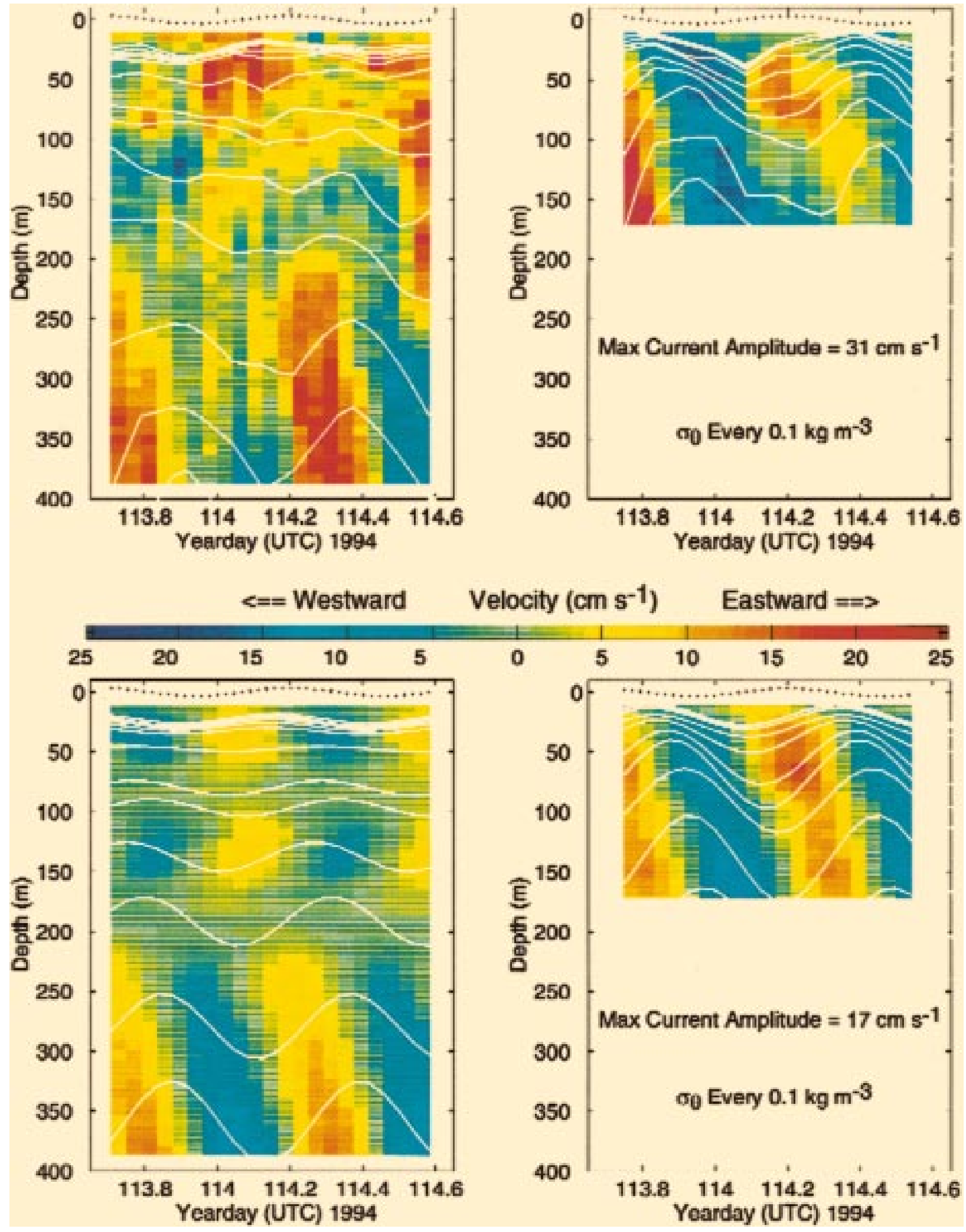

FIG. 9. Time series of observed (upper panels) and $M_{2}$-fit (lower panels) east-west velocity component and isopycnal displacements for deep station A2 (left) and shallow station A1 (right) during ITEX1. Demeaned $M_{2}$ sea level oscillations exaggerated by a factor of 10 (dashed lines) are also shown. 


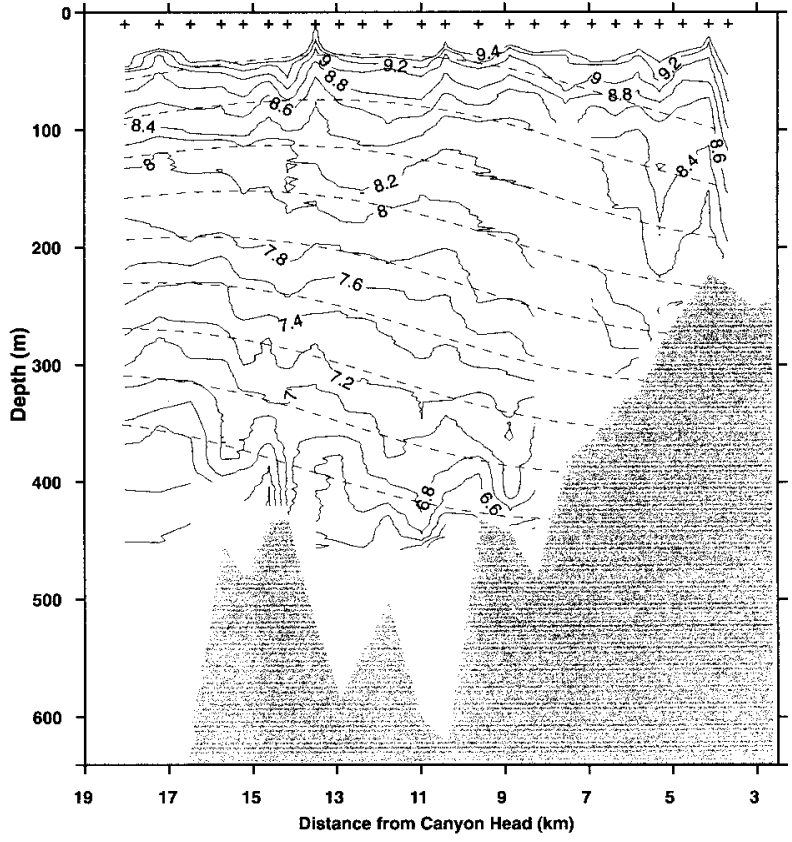

FIG. 10. An along-canyon temperature section determined from 24 XBT drops (+) obtained between 1724-1818 UTC 25 April 1994 during ITEX1, compared with theoretical isopycnal displacements (dashed) computed from the polarization equations for internal waves, using $L_{x}=30 \mathrm{~km}, L_{z}=1.2 \mathrm{~km}, N=3.5 \times 10^{-3} \mathrm{~s}^{-1}, f=0$, and $u_{o}=15 \mathrm{~cm} \mathrm{~s}^{-1}$. Time of high tide was 1819 UTC.

In order to compare these time series results to the spatial snapshot collected in ITEX1, the along-canyon XBT section is compared with a theoretical $\rho^{\prime}$ field in Fig. 10. For this comparison, which spans depths of 50$450 \mathrm{~m}, u_{o}=15 \mathrm{~cm} \mathrm{~s}^{-1}$, typical of the ADCP time series, is used to calculate $\rho^{\prime}$ from the polarization equations with $f=0, m=5.2 \times 10^{-3} \mathrm{~m}^{-1}$ (as observed at the deep CTD station), $k=2.1 \times 10^{-4} \mathrm{~m}^{-1}$ (which yields the observed $\theta=2.3^{\circ}$ ); and $N=3.5 \times 10^{-3} \mathrm{~s}^{-1}$ [also chosen so that $\theta=2.3^{\circ}$, using Eq. (1)]. Only the upper one-third $(0 \leq m z \leq 2 \pi / 3)$ and the eastern one-half $(\pi$ $\leq k x \leq 2 \pi)$ of the theoretical density field are depicted, at time $\omega t=0$. The temperature data was collected over a 56-minute time span as the ship cruised westward along the canyon axis. The last XBT was dropped at 1818 UTC, 1 min prior to the predicted high tide at Monterey. Of the $27 \mathrm{XBTs}$ dropped, the first two and last one indicated abnormally high temperatures and were discarded. Another XBT profile obtained $6 \mathrm{~km}$ from the canyon head indicated abnormally high temperatures below $100 \mathrm{~m}$, and only part of the profile was used.

Below $200 \mathrm{~m}$, where the buoyancy frequency is fairly constant, the slope of the isotherms (60-m depth change over $9-10 \mathrm{~km})$ is in excellent agreement with the sinusoidal shape of the theoretical density field. Superimposed on this mesoscale internal tide oscillation are finescale $[O(1 \mathrm{~km})]$ oscillations of considerable amplitude. These smaller-scale oscillations are barely re- solved by the XBT sampling scheme, but are consistent with the hydraulic jumps associated with the internal tides observed by Holloway (1991) on the Australian North West Shelf. Similar small-scale features may have been aliased in the ITEX CTD and ADCP measurements and are considered a possible source of error in fitting an $M_{2}$ wave to the observations.

Unlike the ITEX1 observations, the ITEX2 currents and isopycnals reveal a standing wave pattern (Fig. 11). Abrupt $180^{\circ}$ phase shifts in $u$ occur between 50 and 100 $\mathrm{m}$ at station $\mathrm{B} 2$ and above $50 \mathrm{~m}$ at station $\mathrm{B} 1$. A $180^{\circ}$ phase shift also occurs in $\rho^{\prime}$ above $50 \mathrm{~m}$ at B2 but is more easily seen in the phase plot of Fig. 5. Below these depths, the phase of $u$ and $\rho^{\prime}$ at both stations is essentially constant with depth. Internal tides on the continental shelf are typically observed to propagate in the first mode, that is, standing in $z$ and propagating shoreward (Baines 1986). In such a case, $u$ and $\rho^{\prime}$ are $180^{\circ}$ out of phase in the upper part of the water column (above the thermocline) and in phase in the lower part due to a $180^{\circ}$ phase shift in $u$ across the thermocline. The middepth node in $u$ in such a case corresponds to a maximum in $w$ and $\rho^{\prime}$. In the ITEX2 observations, $u$ leads $\rho^{\prime}$ by $90^{\circ}$. This phase relationship can exist along certain portions of an internal wave that is standing in both $z$ and $x$. Unlike progressive waves, the phase relationships among $u, v, w$, and $\rho^{\prime}$ in standing waves have spatial dependence. The behavior of the first mode, flat-bottom internal seiche (i.e., an internal wave standing in two dimensions) is useful for a general description of how the phase relationships among $u, w$, and $\rho^{\prime}$ differ between progressive and standing waves. The applicable polarization equations for a wave standing in both $x$ and $z$ are

$$
\begin{aligned}
u & =\frac{k \omega}{\left(\omega^{2}-f^{2}\right)} \frac{p_{o}}{\rho_{o}} \sin (k x) \cos (m z) \sin (\omega t) \\
v & =\frac{k f}{\left(\omega^{2}-f^{2}\right)} \frac{p_{o}}{\rho_{o}} \sin (k x) \cos (m z) \cos (\omega t) \\
w & =-\frac{m \omega}{\left(N^{2}-\omega^{2}\right)} \frac{p_{o}}{\rho_{o}} \cos (k x) \sin (m z) \sin (\omega t) \\
\rho^{\prime} & =\frac{N^{2} m p_{o}}{g\left(N^{2}-\omega^{2}\right)} \cos (k x) \sin (m z) \cos (\omega t) .
\end{aligned}
$$

There is no vertical component of flow at any point along the wave at times $\omega t=0$ and $\omega t=\pi$, when the isopycnals are at their maximum deflection, and the only horizontal flow is due to $v$. Maximum $u$ and $w$ velocities occur one-quarter of a cycle later. As seen in Fig. 19 of Petruncio (1996), in the quadrants bounded by $0<k x$ $<\pi / 2$ and $\pi<k x<3 \pi / 2$ in the upper half of the water column and by $\pi / 2<k x<\pi$ and $3 \pi / 2<k x<$ $2 \pi$ in the lower half, $u$ leads $\rho^{\prime}$ by $90^{\circ}$ as observed in ITEX2. Additionally, nodes in $u$ and $w$ (or $\xi$ ) are collocated as appears to be the case in ITEX2.

That the observed $180^{\circ}$ phase shifts in $u$ occur at 

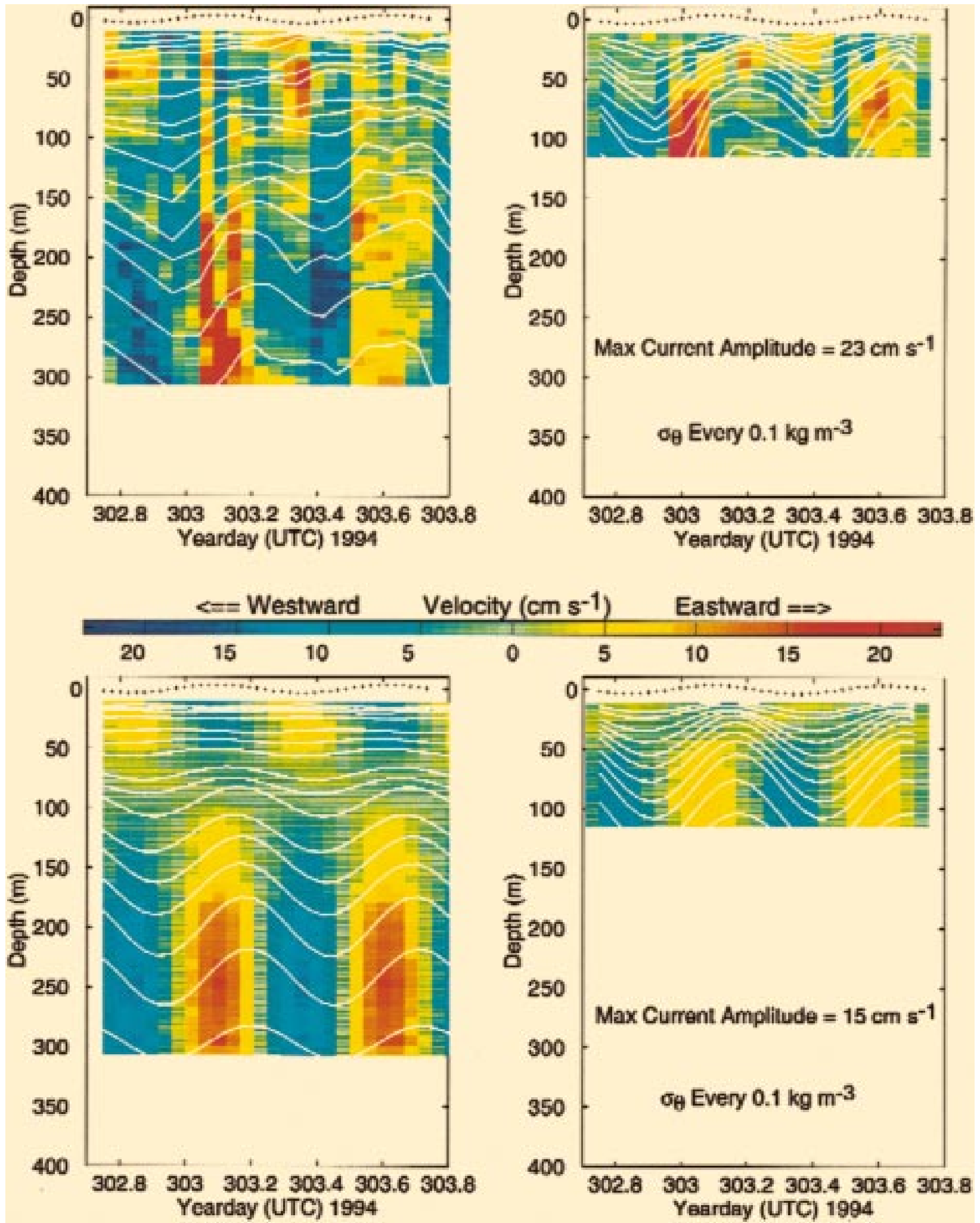

FIG. 11. Observed current and isopycnal oscillations and $M_{2}$ wave fits during ITEX2 at deep station B2 (left) and shallow station B1 (right), as in Fig. 9. 


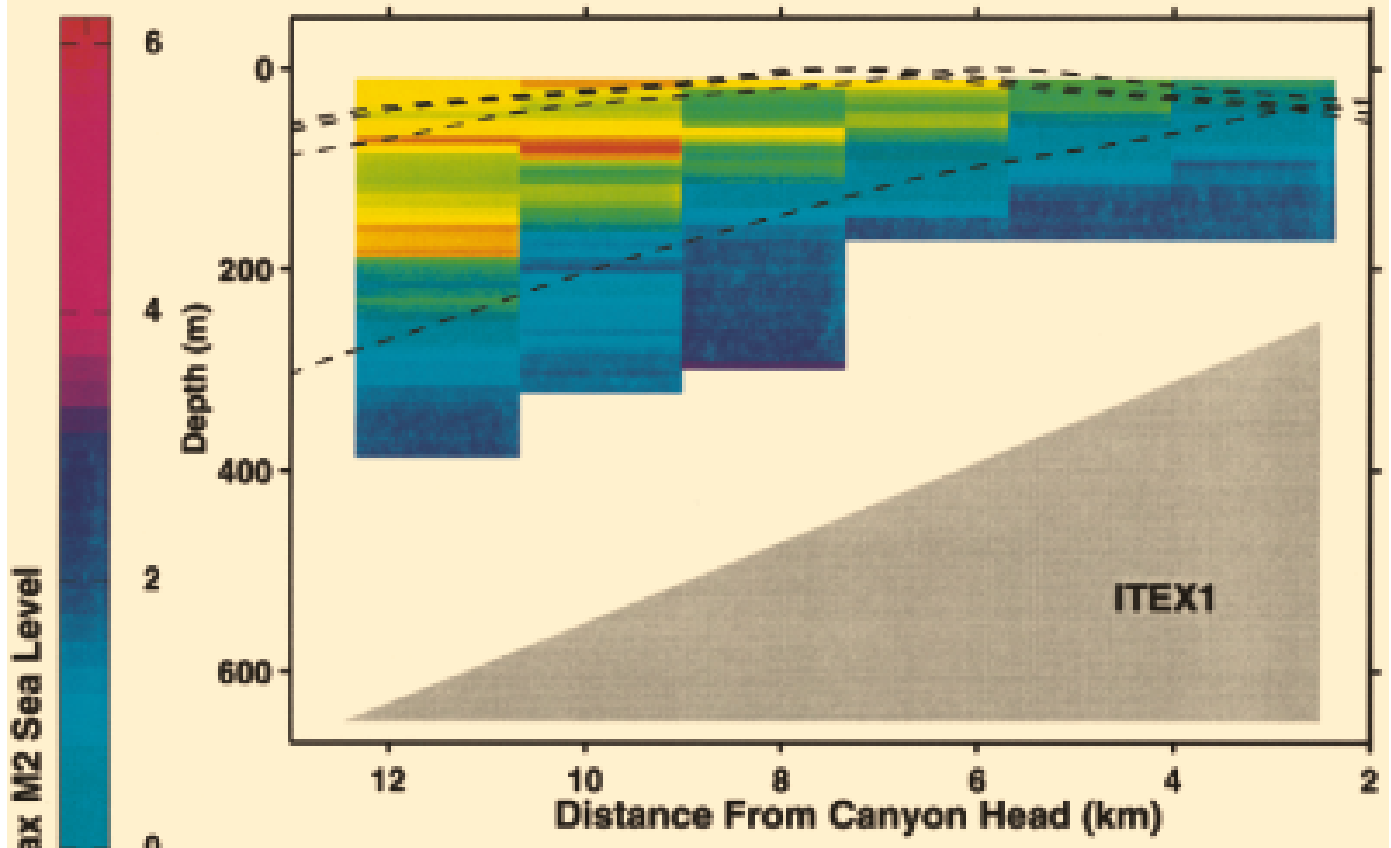

0

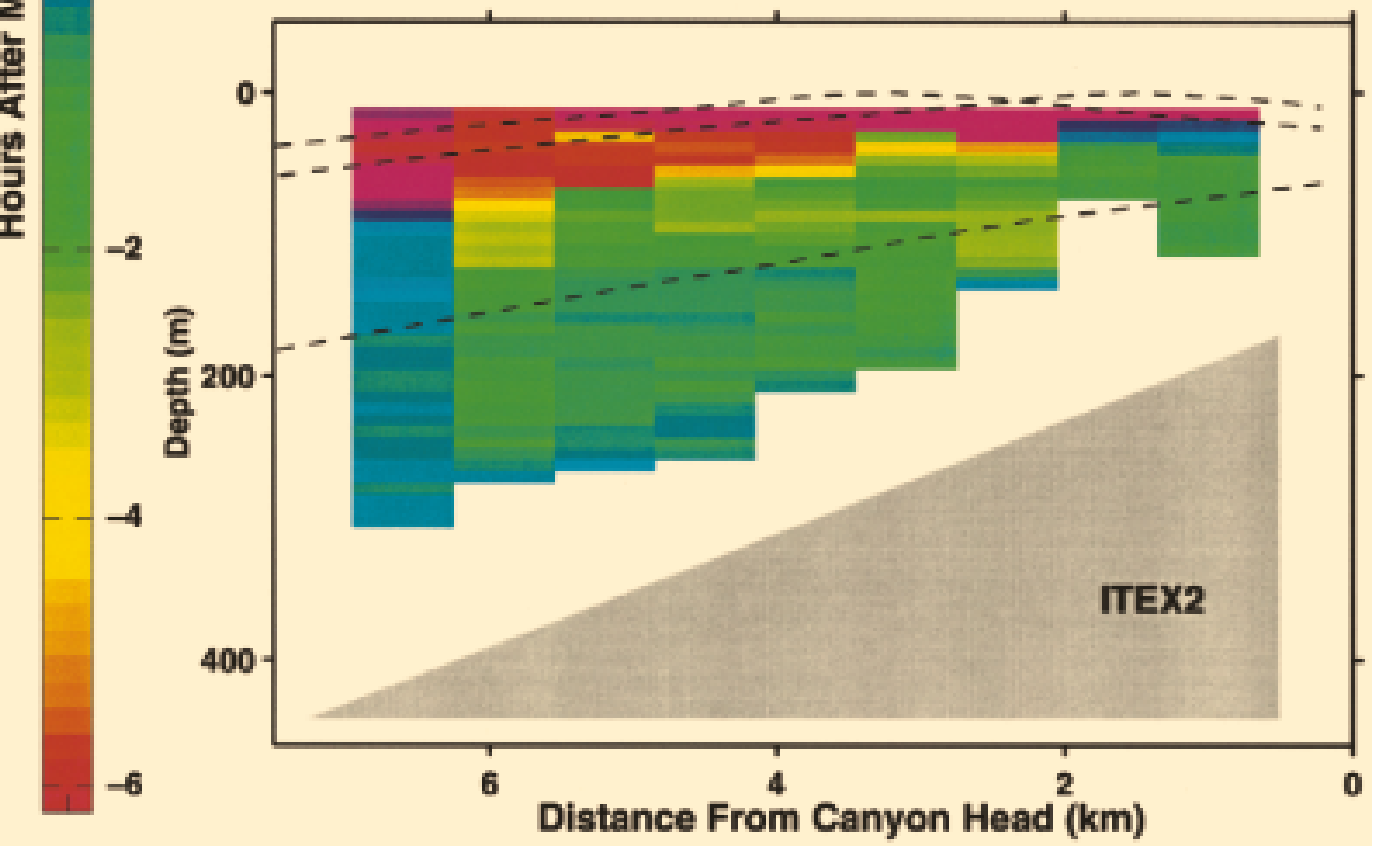

FIG. 12. Phase of $M_{2}$ east-west velocity relative to the phase of $M_{2}$ sea level for each ADCP bin during ITEX1 (upper) and ITEX2 (lower), with the theoretical $M_{2}$ characteristics from Fig. 20 overlain (dashed lines). Positive phase indicates that maximum eastward (shoreward) flow occurs after high $M_{2}$ surface tide.

different depths at each ITEX2 along-canyon station suggests that the internal tide during this period is standing along the characteristic, in the manner of the basin internal seiches depicted in Maas and Lam (1995). This pattern is seen clearly in Fig. 12, which depicts the phases of the $M_{2} u$ oscillations observed at each alongcanyon geographic bin in ITEX1 and ITEX2. While the ITEX1 $u$ phases steadily increase with depth from -2 $\mathrm{h}$ (leading the $M_{2}$ sea level oscillations) to $+2 \mathrm{~h}$ (lagging sea level), the ITEX2 phases abruptly shift from $\pm 6 \mathrm{~h}$ $\left(180^{\circ}\right.$ out of phase with sea level) to values between 0 and $-2 \mathrm{~h}$ (nearly in phase with sea level). The depth of the abrupt phase shift, which corresponds to the depth of the nodes in the $M_{2}$ ellipse plots (Fig. 8), decreases toward the canyon head at a rate that matches the slope of the $M_{2}$ characteristics. The dashed lines superimposed 
on Fig. 12 represent $M_{2}$ characteristics calculated from the $N$ profiles observed at the deep and shallow ITEX2 CTD stations. The source regions for these characteristics (i.e., the internal tide generation sites) are discussed in section 5. A modal description of the observed standing wave pattern is also presented in section 5 .

\section{d. Cross-canyon observations}

\section{1) Density}

Cross-canyon CTD and ADCP measurements were conducted during the second half of ITEX2. These measurements, like the ITEX2 along-canyon measurements, revealed large amplitude isopycnal and current oscillations with little vertical phase propagation at depths greater than $90 \mathrm{~m}$ (Fig. 13). The isopycnal oscillations observed at the midcanyon site (C3) during this time period are depicted in Fig. 5, and data from the CTD station on the northern rim (C5) is not displayed since the internal tide at that site was very weak $(<4 \mathrm{~m}$ in amplitude). The percent variance accounted for by the $M_{2}$ fit, as well as the $M_{2}$ amplitudes and phases, are plotted versus depth for the axis station (C3) as well as those at the north wall (C4), south wall (C2), and southern rim $(\mathrm{C} 1)$. The observed oscillations are well represented by the $M_{2}$ wave fit, which accounts for up to $90 \%$ of the observed variance in isopycnal depth. The $M_{2}$ amplitudes are somewhat stronger on the southern side of the canyon (C2), with maximum values of nearly $40 \mathrm{~m}$. The 12-m amplitude oscillations over the southern rim are the strongest observed at the 50-60-m depth range. Below $90 \mathrm{~m}$, the phase of the isopycnals is nearly constant, lagging the sea level oscillations by approximately $2 \mathrm{~h}$. The constant phase with depth is consistent with the ITEX2 along-canyon observations of the density field.

Snapshots of the isopycnal displacements at two points in the tidal cycle, based upon the harmonic analysis results, are depicted in Fig. 14. At 0500 UTC 31 October, $2 \mathrm{~h}$ after the high tide recorded at the Monterey tide gauge, the isopycnals are at their maximum upward displacement. Six hours later, they are at their lowest depths. The depth excursions are much greater on the south side of the canyon than on the north side, and the "tidal pumping" (Shea and Broenkow 1982) of cooler, denser water over the southern rim of the canyon is readily apparent in the depth change of the $25.78 \mathrm{~kg}$ $\mathrm{m}^{-3}$ isopycnal $\left(10.47^{\circ} \mathrm{C}\right.$ isotherm). Very little change in isopycnal depth is seen on the north side of the canyon.

\section{2) Currents}

The $u$ velocity components measured during the cross-canyon transects (not shown) are much more energetic than the $v$ components, with variances up to $120-140 \mathrm{~cm}^{2} \mathrm{~s}^{-2}$ over much of the cross section and $80 \%-90 \%$ of the variance accounted for by the $M_{2}$ fit.
The variances of the $v$ components are generally less than $25 \mathrm{~cm}^{2} \mathrm{~s}^{-2}$. The $M_{2}$ tidal ellipses (Fig. 15) are nearly rectilinear, and those representing the stronger currents $\left(20 \mathrm{~cm} \mathrm{~s}^{-1}\right)$ are almost uniformly oriented in the along-canyon direction. An exception to this pattern exists over the southern rim, where the near-bottom currents are oriented in the north-south direction, normal to the isobaths. The relatively strong isopycnal oscillations and the cross-isobath orientation of the ellipses over the southern rim suggest that internal tide generation is occurring along this portion of the canyon. At most ADCP stations, a minimum in $M_{2}$ horizontal velocity exists at depths of 50-60 m. A phase shift of approximately $180^{\circ}$ in the $u$ velocity component also occurs over this depth range, which is consistent with a node in a standing wave, and with the pattern of the $M_{2}$ ellipses (Fig. 8) and $M_{2} u$ phases (Fig. 12) derived from the ITEX2 along-canyon measurements.

\section{e. Near-bottom current and temperature oscillations}

Time series of the hourly S4 velocity and temperature data for 200016 May to 130021 June 1991 are depicted in Fig. 16, together with hourly sea level at Monterey. Strong semidiurnal and diurnal oscillations are apparent throughout the velocity and temperature records. The spring-neap cycle of 6-21 June (hours 480-840) is well-represented in both velocity and temperature, although with a slight lag relative to sea level. A lowfrequency modulation, with a period of roughly 10 days, is also present in the temperature record. The currents regularly attained speeds of $20-30 \mathrm{~cm} \mathrm{~s}^{-1}$, and the maximum recorded velocity was $41.2 \mathrm{~cm} \mathrm{~s}^{-1}$. Examination of temperature and velocity spectral densities revealed strong diurnal and semidiurnal peaks, and lesser peaks in the terdiurnal (8-h period) and quarterdiurnal (6-h period) bands. The results of least squares harmonic analysis of the temperature and velocity records are presented in Tables 3 and 4. Thirty-six constituents were resolved in the analyses; however only those constituents that figured prominently in both the temperature and velocity analyses are listed. The $P_{1}$ constituent was inferred from $K_{1}$, based on their amplitude and phase relationships in the yearlong tidal height analysis. The method for determining the standard deviations associated with the tidal analysis results is discussed in Petruncio (1996).

\section{1) Temperature}

The amplitudes of the temperature perturbations $\left(T^{\prime}\right)$ listed in Table 3 represent deviations from the mean temperature of $7.0^{\circ} \mathrm{C}$. If the background stratification is assumed to be stable, $T^{\prime}$ can be assumed to be $180^{\circ}$ out of phase with the vertical displacement of the $7.0^{\circ} \mathrm{C}$ isotherm. The strongest temperature oscillations occurred at the $M_{2}, K_{1}$, and $O_{1}$ frequencies, which are also the strongest constituents in the surface tide. Significant 

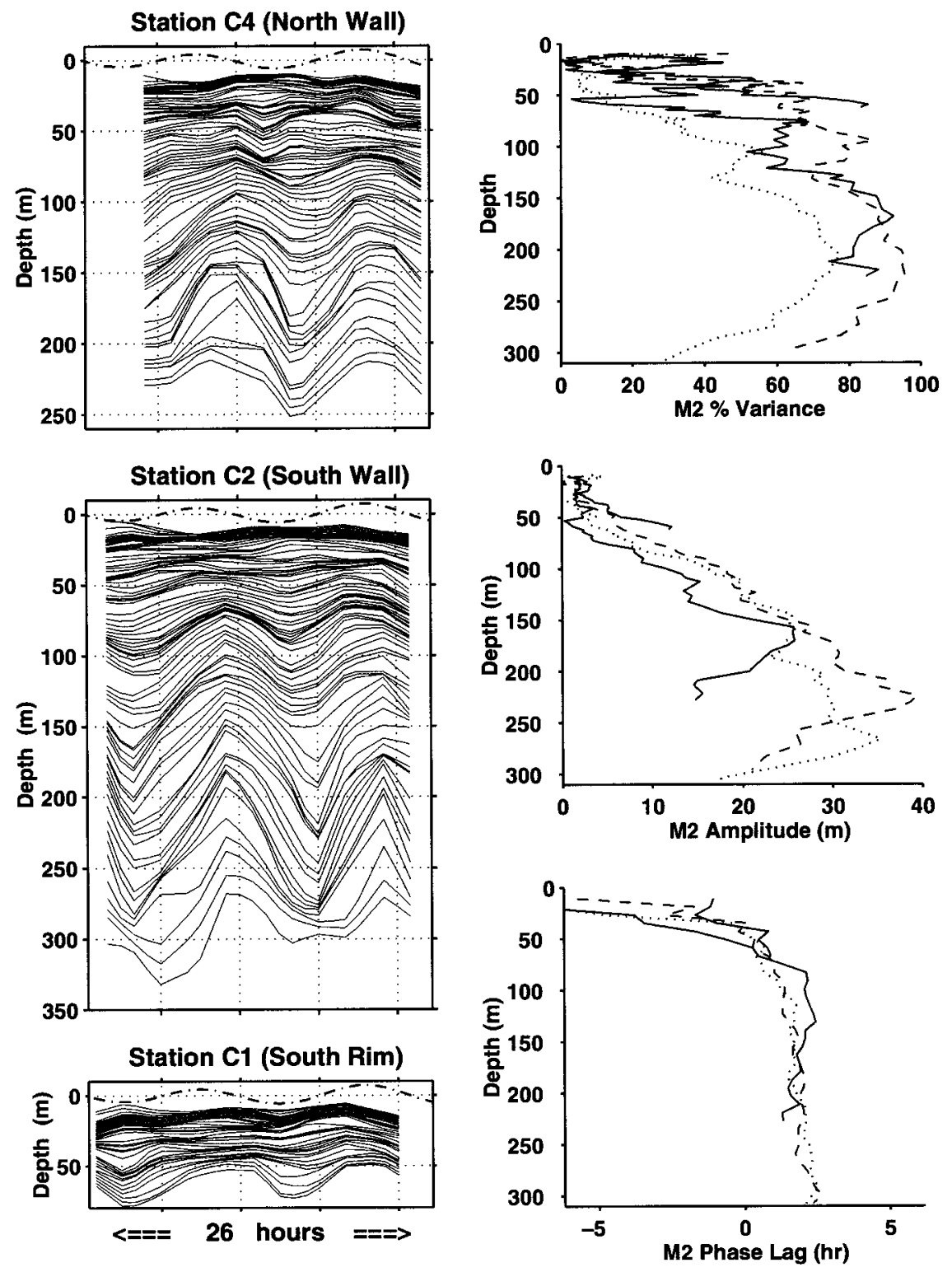

FIG. 13. Time series of isopycnal depths at $0.02 \mathrm{~kg} \mathrm{~m}^{-3}$ intervals (solid) and sea level (dashed) during ITEX2 at the north wall (upper left), south wall (middle left), and south rim (lower left) CTD stations during ITEX2. Sea level oscillations were demeaned and exaggerated by a factor of 10. Percent variance described (upper), amplitude (center), and phase (lower) for the fit of an $M_{2}$ wave over $\sim 25 \mathrm{~h}$ are shown in the right panels as a function of depth at the north wall (solid, deeper), south wall (dashed), midaxis (dotted), and south rim (solid, shallower) stations.

amplitudes were also attributed to three other semidiurnal frequencies $\left(N_{2}, L_{2}\right.$, and $\left.S_{2}\right)$ and to the quarterdiurnal constituent $\mathrm{SN}_{4}$.

A comparison of the Greenwich phases of the $M_{2}$ internal tide (as inferred from the phase of $T_{M_{2}}^{\prime}, 146.5^{\circ}$ $+180^{\circ}=326.5^{\circ}$ ) and the $M_{2}$ surface tide measured at Monterey $\left(181.9^{\circ}\right)$ suggests that the near-bottom $M_{2}$ internal tide during this period lagged the surface tide by $144.6^{\circ}$. Taking into account the error bounds on the phase of $T_{M_{2}}^{\prime}$, this phase lag is equal to $4.7-5.3 \mathrm{~h}$, consistent with the phase values observed in the lower part of the water column during ITEX1 (Fig. 4). Similar phase lags exist for the $N_{2}$ and $L_{2}$ internal tides (relative to the $N_{2}$ and $L_{2}$ surface tides); however, the inferred lag between the $S_{2}$ surface and internal tides is somewhat less, at 1.3-3.3 h. The relative proportions of the $N_{2}, M_{2}$, and $S_{2} T^{\prime}$ amplitudes are roughly the same as in sea level $\left(T_{M_{2}}^{\prime}: T_{N_{2}}^{\prime}=2.8: 1\right.$, versus $4.4: 1$ in sea level, and $T_{M_{2}}^{\prime}: T_{S_{2}}^{\prime}=3.4: 1$, versus $3.7: 1$ in sea level). The amplitude of the $L_{2}$ temperature perturbation is disproportionately strong (compared to the relatively small $L_{2}$ sea level amplitude of $3.1 \mathrm{~cm}$ ), and may indicate a 

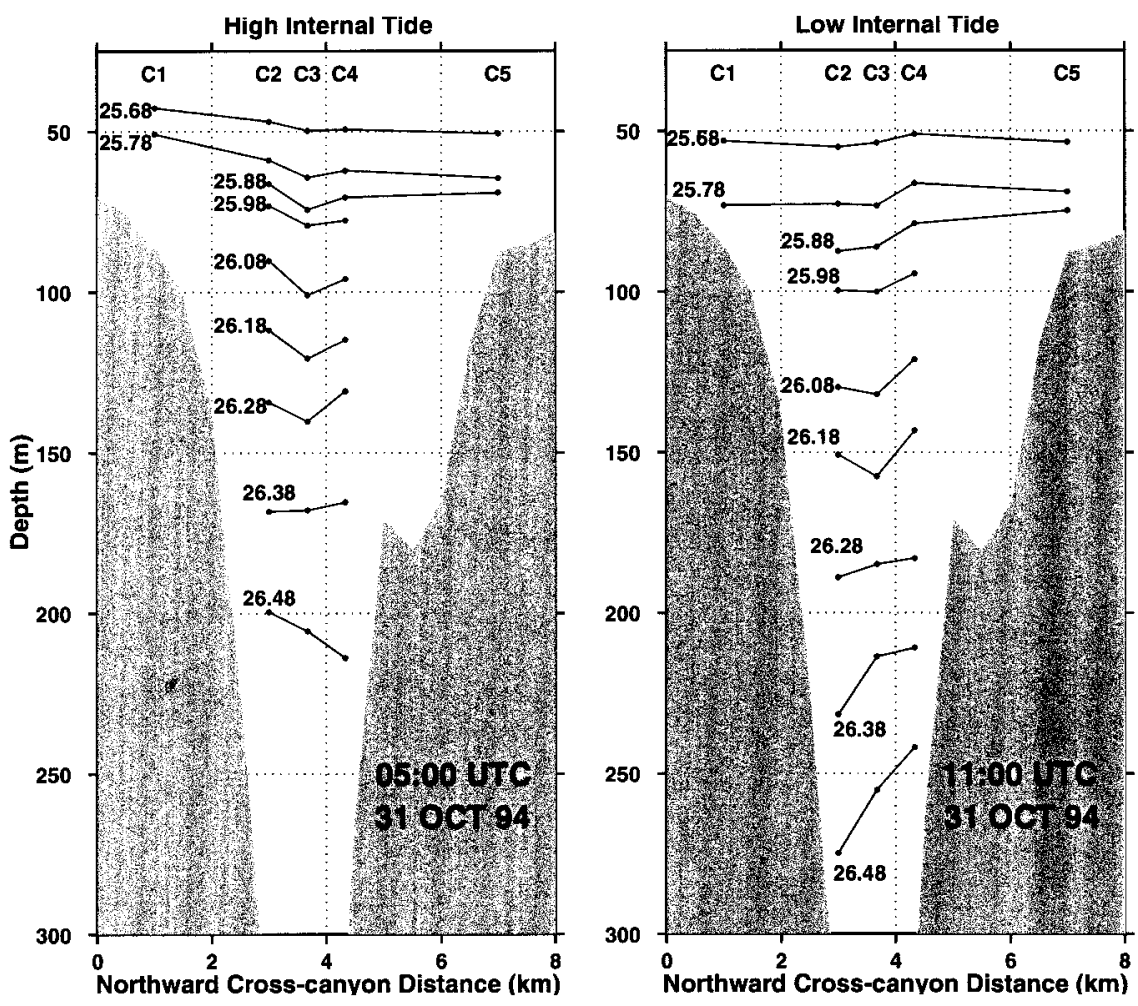

FIG. 14. Snapshots of cross-canyon density field $\left(\sigma_{\theta}\right)$ during ITEX2.

spread of $M_{2}$ energy to this neighboring frequency due to variability in the generation and propagation of the $M_{2}$ internal tide.

The $\mathrm{SN}_{4}$ constituent was the strongest quarterdiurnal constituent in both the temperature and velocity analyses. Given that $S N_{4}$ results from nonlinear interactions of the $S_{2}$ and $N_{2}$ constituents, the phase of $S N_{4}$ should be equal to the sum of the $S_{2}$ and $N_{2}$ phases. This holds true for the temperature analysis $\left(S N_{4}\right.$ phase $=178^{\circ} \pm$ $13.8^{\circ}$, and the $S_{2}$ phase $+N_{2}$ phase $=191.6^{\circ} \pm 56.2^{\circ}$ ), but not for the currents analysis. If, in fact, strong interaction is occurring between $S_{2}$ and $N_{2}$, one might expect a difference-frequency harmonic to be present. The period of the theoretical low-frequency harmonic would be 9.6 days, and it is tempting to consider this as a potential explanation for the roughly 10-day modulation of the temperature record. It is not clear, however, why the $S_{2}-N_{2}$ interaction should be favored over interactions involving the strong $M_{2}$ constituent.

\section{2) Currents}

The lengths of the semimajor and semiminor axes, the Greenwich phases, and the inclinations of the tidal current ellipses (in degrees counterclockwise from due east) are presented in Table 4. A negative value for the semiminor axis indicates clockwise rotation of the currect vector. As with the temperature perturbations, the strongest constituent in the velocity record is the $M_{2}$, and the ratio of the $M_{2}$ semimajor axis length to those of the $N_{2}, L_{2}$, and $S_{2}$ constituents is nearly identical to the ratios of the respective $T^{\prime}$ amplitudes (2.4-2.7:1). The $M_{2}, N_{2}$, and $L_{2}$ currents lag their respective high tides by $2-3 \mathrm{~h}$ (1/6-1/4 cycle), and lead their respective isotherm displacements (as inferred from the $T^{\prime}$ analysis) by $2-3 \mathrm{~h}$, consistent with progressive internal waves. The $S_{2}$ currents lead the $S_{2}$ isotherm displacements by nearly $2 \mathrm{~h}$ and are nearly in phase with $S_{2}$ sea level. A possible explanation for the shorter phase lag between the $S_{2}$ internal and surface tides is that the generation site for the $S_{2}$ internal tide is closer to the mooring than the sites at which the other semidiurnal constituents are generated.

As in the $T^{\prime}$ analysis, the $L_{2}$ constituent is disproportionately strong. That the $L_{2}$ ellipse inclination and phase are not significantly different from those of the $M_{2}$ constituent is further evidence that the $L_{2}$ signal is a result of energy spread from the $M_{2}$ constituent. Godin (1991) notes that the power spectrum of a current record (as opposed to a sea level record) is likely to be contaminated due to bathymetric steering of the flow and spatial changes in current flow during large and small tides; individual spectral lines may be broadened due to asymmetric flow reversals.

Indeed, the current reversals depicted in Fig. 16 are asymmetric, flowing toward $210^{\circ} \mathrm{T}$ in the downcanyon direction and toward $040^{\circ} \mathrm{T}$ in the upcanyon direction. Strong upcanyon flow tends to be aligned with the can- 


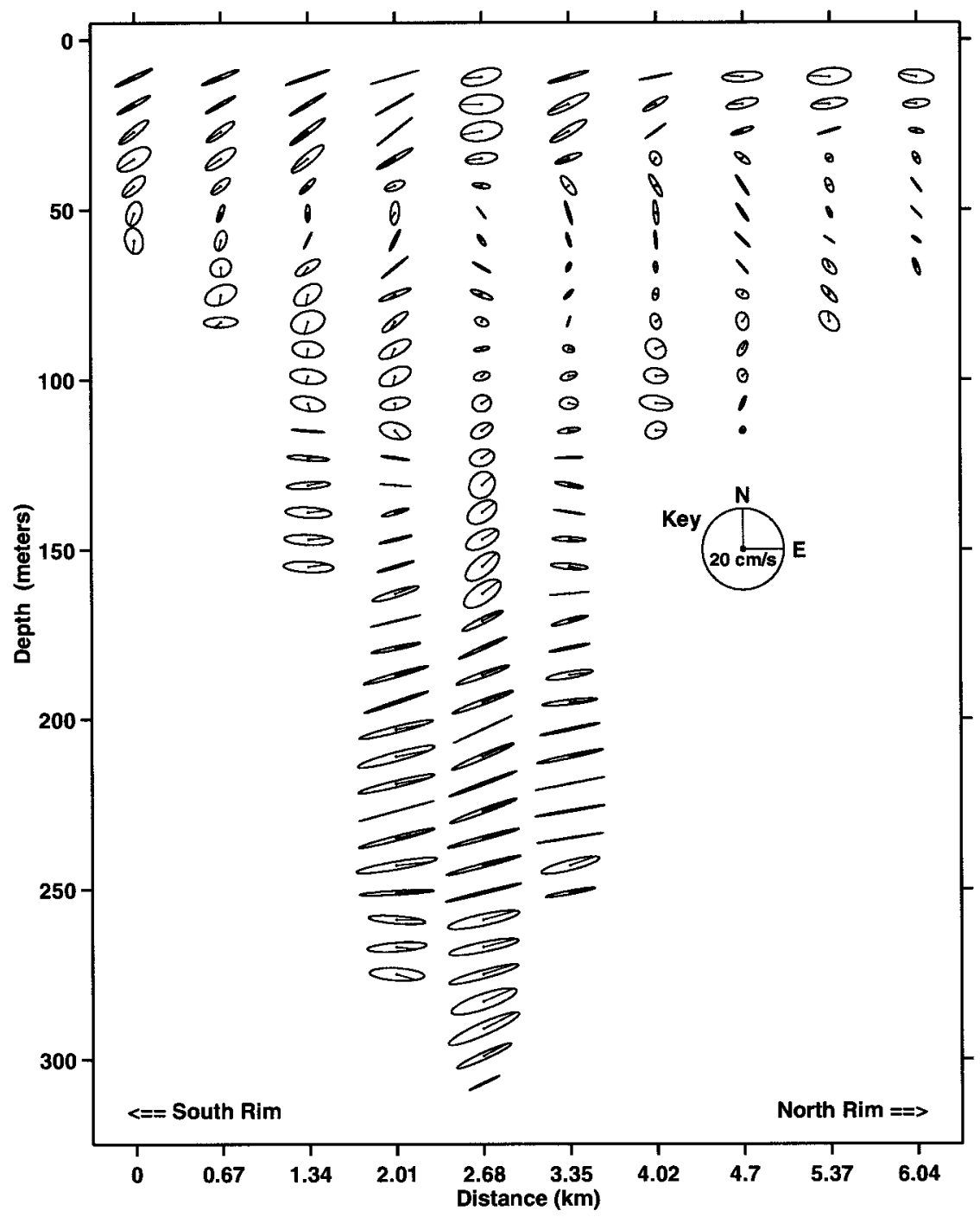

FIG. 15. Cross-canyon $(y-z)$ section of $M_{2}$ horizontal current ellipses during ITEX2. Ellipses are centered on the ADCP bins and the line extending from the center of each ellipse represents the current speed and the direction toward which current flows at the time of high $M_{2}$ sea level.

yon axis, while strong downcanyon currents tend to flow toward the south-southwest $\left(210^{\circ} \mathrm{T}\right)$ with a cross-canyon component. This asymmetric flow resulted in a mean flow of $5.0 \mathrm{~cm} \mathrm{~s}^{-1}$ due southward. Similar bimodal patterns in current flow were observed in the near-bottom current measurements made in MSC by Shepard et al. (1979). The asymmetric flow may be simply a result of local bathymetric effects. Alternatively, the asymmetric flow could result from the proximity of the current meter to the north wall of this $\mathrm{V}$-shaped canyon (Petruncio 1996). In the presence of a progressive internal wave, such as these data suggest, the vertical and along-canyon horizontal velocity components are in phase. Diversion of downward velocity towards the cross-canyon direction, combined with the flow directed seaward along the canyon, would result in deflection of the downcanyon flow in the sense observed.

\section{f. Energetics}

Assuming the velocity and density vary sinusoidally over the tidal cycle, the mean perturbation energy per unit volume for the internal tide is

$$
E=\frac{1}{4} \rho_{o}\left(u_{o}^{2}+v_{o}^{2}+w_{o}^{2}\right)+\frac{1}{4} \frac{g^{2} \rho_{o}^{\prime 2}}{\rho_{o} N^{2}},
$$

where $u_{o}, v_{o}$, and $w_{o}$ are the $M_{2}$ velocity amplitudes and $\rho_{o}^{\prime}$ is the amplitude of the $M_{2}$ density perturbation (not to be confused with $\rho_{o}$, the average density at a given depth). The first term represents the mean perturbation kinetic energy (KE), and the second represents the mean perturbation potential energy (PE). The values of mean perturbation PE and KE calculated from the ITEX1 and ITEX2 along-canyon measurements, made over $25 \mathrm{~h}$, are plotted versus depth in Fig. 17. The semimajor and 

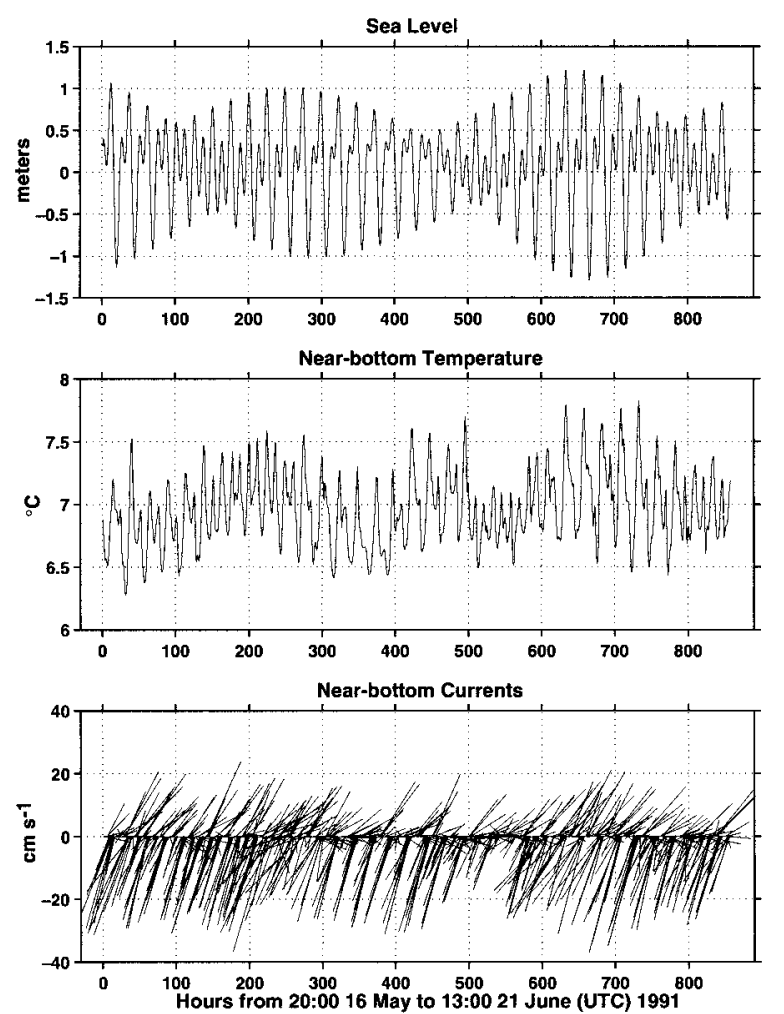

FIG. 16. Demeaned sea level from the Monterey tide gauge (upper) with temperature (middle) and velocity (bottom) from the S4 current meter $2 \mathrm{~m}$ above the 370-m bottom. Stick vectors point away from the zero line toward the direction of flow with northward being up on the page.

semiminor axes of the $M_{2}$ ellipses were used for $u_{o}$ and $v_{o}$ in the KE calculation. The contribution to KE from $w_{o}$ was neglected, since $w_{o}$ (estimated from $\rho^{\prime}$ at the CTD stations) was an order of magnitude smaller than $u_{o}$ and $v_{o}$.

The data from both cruises reveal energy maxima in the lower half of the water column that shoal toward the canyon head at nearly the same angle as the canyon floor. The focusing of energy along an $M_{2}$ characteristic is easier to see in the more closely spaced ITEX2 measurements, remembering that the three stations located $2-3.5 \mathrm{~km}$ from the canyon head are not over the canyon axis (Fig. 3). Near-surface maxima are also present, most noticeably in the ITEX1 data. The near-surface maxima may be a result of internal wave energy propagating in a narrow near-surface beam and will be discussed further in section 5 .

The theoretical ratio of energy distribution in internal gravity waves of semidiurnal tidal frequency, for which energy propatgates nearly horizontally, is approximately (Gill 1982)

$$
\frac{\mathrm{KE}}{\mathrm{PE}}=\frac{\omega^{2}+f^{2}}{\omega^{2}-f^{2}} .
$$

This equation yields a ratio of 2.26, which was rarely observed in the ITEX data. At the CTD stations, where the PE can be estimated, the energy is nearly equally partitioned between KE and PE suggesting (as did the various methods for determining the angle of the wave characteristic) that, due to topographic constraints on cross-canyon motion, better agreement with linear theory is obtained if the motion of the internal tide in the canyon is considered to be irrotational. Both cruises revealed greater PE than KE at the shallow CTD stations, where departure from linear theory is expected due to interaction of the waves with the bottom and sides of the canyon.

Depth-integrated values of energy density were calculated by summing the mean perturbation KE and PE values to obtain total energy (TE), multiplying each of the TE values by $8 \mathrm{~m}$ (the size of the ADCP bins), and summing over the water column. For those depths reached only by the CTD, TE was estimated by doubling the PE. The resulting energy density values for ITEX 1 are 2343 and $1638 \mathrm{~J} \mathrm{~m}^{-2}$ at the deep and shallow stations, respectively. Somewhat smaller values of 1072 and $1198 \mathrm{~J} \mathrm{~m}^{-2}$ are obtained for the ITEX2 deep and shallow stations, respectively. The ITEX1 and ITEX2 energy densities are comparable to the $1700 \mathrm{~J}$ $\mathrm{m}^{-2}$ reported by Petrie (1975) for an internal tide propagating seaward from a generation site at the Scotian shelfbreak.

The higher energy densities during ITEX1 are most likely due to greater barotropic forcing during that period, compared to ITEX2. The sea level excursions from high to low tide just prior to and during ITEX1 are 1.52 times greater than those prior to and during ITEX2 (Fig. 18). The $M_{2}$ and $S_{2}$ sea level constituents con-

TABLE 3. The S4 tidal temperature perturbations 16 May-21 June 1991.

\begin{tabular}{|c|c|c|c|c|}
\hline $\begin{array}{c}\text { Tidal } \\
\text { constituent }\end{array}$ & $\begin{array}{l}\text { Frequency } \\
\quad(\mathrm{cph})\end{array}$ & $\begin{array}{c}\text { Period } \\
\text { (solar hours) }\end{array}$ & $\begin{array}{l}\text { Amplitude } \\
\left({ }^{\circ} \mathrm{C}\right)\end{array}$ & $\begin{array}{c}\text { Greenwich phase } \\
\text { (deg) }\end{array}$ \\
\hline$O_{1}$ & 0.03873065 & 25.8193446 & $0.126 \pm .03$ & $263.2 \pm 13.6$ \\
\hline$P_{1}$ & 0.04155259 & 24.0658886 & $0.048 \pm .03$ & $330.1 \pm 36.2$ \\
\hline$K_{1}$ & 0.04178075 & 23.9344674 & $0.152 \pm .03$ & $332.4 \pm 11.3$ \\
\hline $\mathrm{N}_{2}$ & 0.07899925 & 12.6583480 & $0.058 \pm .03$ & $122.3 \pm 25.6$ \\
\hline$M_{2}$ & 0.08051140 & 12.4206013 & $0.168 \pm .03$ & $146.5 \pm 8.9$ \\
\hline$L_{2}$ & 0.08202355 & 12.1916206 & $0.060 \pm .03$ & $156.1 \pm 24.8$ \\
\hline$S_{2}$ & 0.08333333 & 12.0000000 & $0.049 \pm .03$ & $69.3 \pm 30.6$ \\
\hline $\mathrm{SN}_{4}$ & 0.16233258 & 6.1601929 & $0.037 \pm .01$ & $178.6 \pm 13.8$ \\
\hline
\end{tabular}


TABLE 4. The S4 tidal currents 16 May-21 June 1991.

\begin{tabular}{ccccc}
\hline \hline Constituent & $\begin{array}{c}\text { Semimajor } \\
\left(\mathrm{cm} \mathrm{s}^{-1}\right)\end{array}$ & $\begin{array}{c}\text { Semiminor } \\
\left(\mathrm{cm} \mathrm{s}^{-1}\right)\end{array}$ & $\begin{array}{c}\text { Greenwich phase } \\
(\mathrm{deg})\end{array}$ & $\begin{array}{c}\text { Inclination } \\
(\text { deg ccw from 090 }\end{array}$ \\
\hline$O_{1}$ & $4.8 \pm 0.6$ & $-0.9 \pm 0.7$ & $13.0 \pm 6.7$ & $50.4 \pm 7.8$ \\
$P_{1}$ & $2.5 \pm 0.7$ & $0.1 \pm 0.5$ & $66.5 \pm 24.9$ & $46.2 \pm 16.9$ \\
$K_{1}$ & $8.3 \pm 0.6$ & $0.3 \pm 0.6$ & $70.1 \pm 4.1$ & $46.2 \pm 4.3$ \\
$N_{2}$ & $5.4 \pm 0.9$ & $0.2 \pm 0.9$ & $224.6 \pm 4.4$ & $46.3 \pm 10.6$ \\
$M_{2}$ & $13.9 \pm 1.0$ & $-2.4 \pm 0.9$ & $266.1 \pm 4.4$ & $40.2 \pm 3.9$ \\
$L_{2}$ & $5.2 \pm 1.0$ & $0.4 \pm 0.9$ & $265.6 \pm 9.0$ & $41.3 \pm 8.0$ \\
$S_{2}$ & $5.7 \pm 1.1$ & $0.2 \pm 0.7$ & $191.0 \pm 11.4$ & $32.2 \pm 7.9$ \\
$S N_{4}$ & $2.4 \pm 0.2$ & $333.4 \pm 36.2$ & $29.4 \pm 82.5$ \\
\hline
\end{tabular}

structively interfere during spring tides and destructively interfere during neap tides. The semidiurnal $u_{o}$, $v_{o}$, and $\rho^{\prime}$ amplitudes used for the energy calculations are based on analyses of short ( $25-50 \mathrm{~h}$ ) record lengths and therefore include contributions from both the $M_{2}$ and $S_{2}$ internal tides (as well as from other weaker semidiurnal constituents that may be present). Thus, the semidiurnal internal tides are expected to be more energetic during spring tides (represented by ITEX1 conditions) than during neap tides (ITEX2). This explanation implies that the internal tide is a result of linear superposition of semidiurnal internal tides with slightly different frequencies. This idea is supported by the nearbottom S4 velocity and temperature measurements in which the ratios of the $M_{2}$ amplitude to those of the $S_{2}$
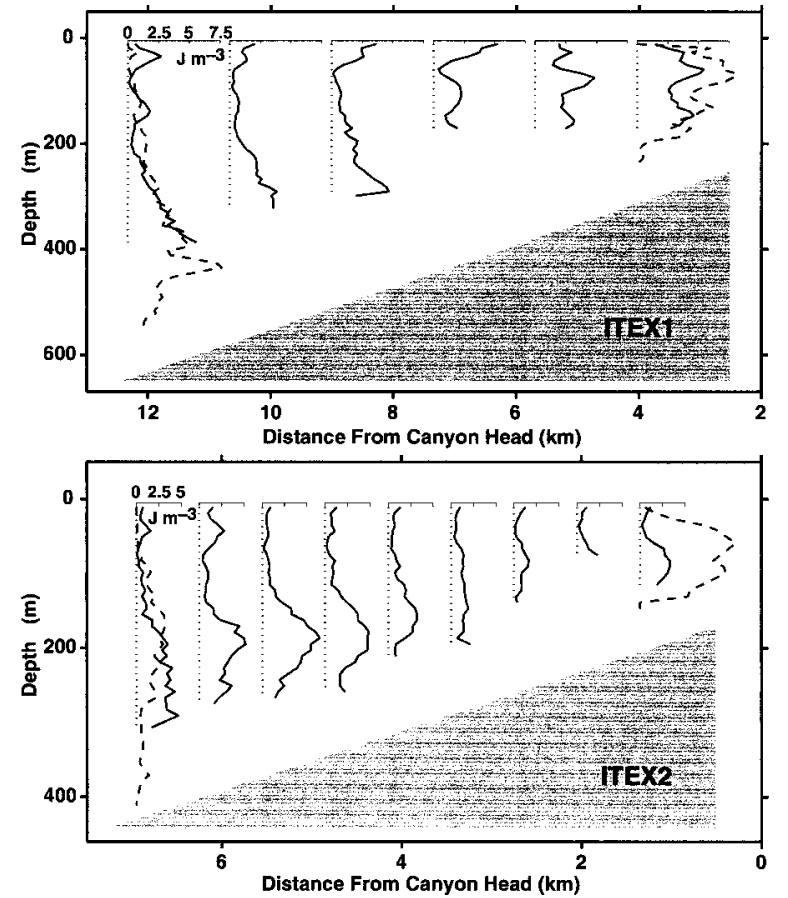

FIG. 17. Kinetic (solid) energy for the $M_{2}$ wave fits during ITEX1 and ITEX2 plotted with the $x$-axis origin for each vertical profile aligned with the center of the along-canyon ADCP bin. Potential energy profiles (dashed) for the canyon-axis CTD stations are also shown. and $N_{2}$ constituents were nearly the same as the corresponding ratios in sea level.

During ITEX1, all indications are that the semidiurnal tide moved onshore as a progressive internal wave. We can, therefore, use these data to estimate energy flux divergence between the deep and shallow stations. Energy flux estimates for ITEX1 were obtained by multiplying the energy density values by the group velocities calculated at A1 $\left(54.9 \mathrm{~cm} \mathrm{~s}^{-1}\right)$ and A2 $(49.2 \mathrm{~cm}$ $\mathrm{s}^{-1}$. This yields energy fluxes of 1286 and $806 \mathrm{~W} \mathrm{~m}^{-1}$ at the deep and shallow stations, respectively. If the difference in energy flux between the two stations were due solely to dissipation, the dissipation per unit volume can be calculated by dividing the difference in energy fluxes by the area of a cross-shore (along canyon) slice between the two stations. Although the area of the along-canyon slice $\left(3.7 \times 10^{6} \mathrm{~m}^{2}\right)$ includes the whole
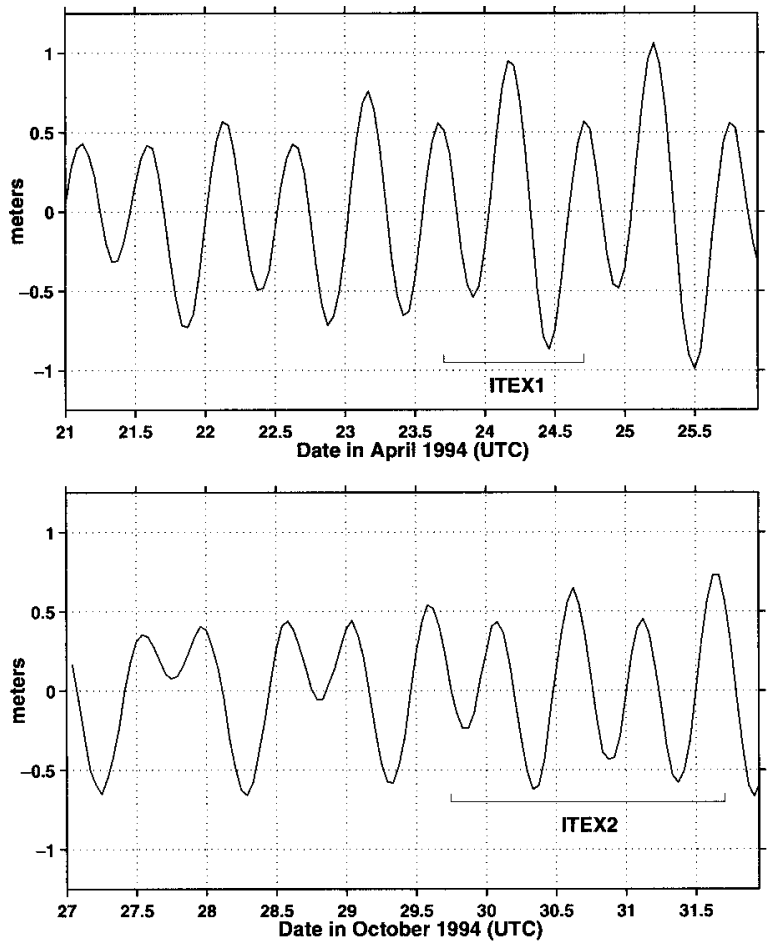

FIG. 18. Demeaned sea level at Monterey during ITEX1 and ITEX2. 
water column, we expect that most of the dissipation takes place through turbulent mixing in the bottom boundary layer along the floor and walls of the canyon. The dissipation is estimated to be $1.3 \times 10^{-4} \mathrm{~W} \mathrm{~m}^{-3}$, which is comparable to the value of $1.42 \times 10^{-4} \mathrm{~W} \mathrm{~m}^{-3}$ calculated by Holloway (1984) for the internal tide on the Australian North West Shelf.

If the $806 \mathrm{~W} \mathrm{~m}^{-1}$ flux at the shallow station were dissipated along the final $3 \mathrm{~km}$ of the canyon length, over a cross-sectional area of approximately $5 \times 10^{5}$ $\mathrm{m}^{2}$, the resulting value of dissipation over that part of the canyon would be $1.6 \times 10^{-3} \mathrm{~W} \mathrm{~m}^{-3}$. Alternatively, a significant portion of the energy flux divergence at the head of the canyon could be directed to the pumping of cool water onto the flanks of the canyon, as discussed by Shea and Broenkow (1982) and seen in ITEX2 (Fig. 14).

The above methodology, which assumes a boxshaped canyon, yields a conservative estimate of the dissipation between the deep and shallow axial stations since it neglects the expected increase in energy density at the shallow station due to the narrowing of the canyon walls. The cross-sectional area of the canyon decreases between the two stations by a factor of roughly 8 . Ignoring any dissipation or generation between the two stations, the energy density at the shallow station would be expected to be $18744 \mathrm{~J} \mathrm{~m}^{-2}$. Using the same value of group velocity as in the previous calculation, the energy flux at the shallow station would be $9222 \mathrm{~W}$ $\mathrm{m}^{-1}$. An upper limit on the rate of dissipation between the two stations can be estimated by taking the difference between the shallow station energy flux estimated from the deep station observations and the energy flux measured at the shallow station $(9222-806=8416$

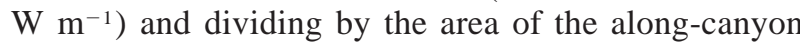
slice. This estimate yields a dissipation rate between the two stations of $2.3 \times 10^{-3} \mathrm{~W} \mathrm{~m}^{-3}$, an order of magnitude greater than the estimate that neglects the decrease in cross-sectional area between stations.

\section{Discussion}

\section{a. Possible internal tide generation sites}

In order to assess the potential variability of the internal tide, it is necessary to identify the generation site. Once this has been accomplished, the effect of mean currents and stratification changes at the generation site, and along the propagation path, can be addressed. The beamlike propagation of internal tide energy upward and eastward through the water column in ITEX1 suggests that the internal tide observed in this part of the MSC is generated in deep water, somewhere west (downcanyon) of the ITEX sites. Using the north and south walls of the canyon within the bay as limits, a wedge of possible propagation paths is depicted in Fig. 19. Although there is evidence that the internal tide is steered by the canyon walls, we are assuming here that it cannot follow

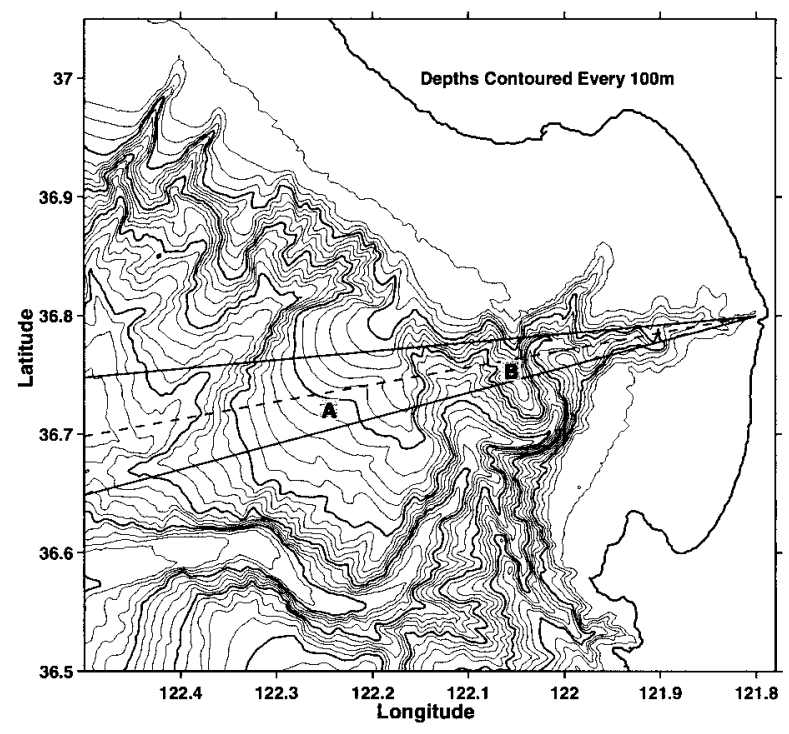

FIG. 19. Likely generation sites for internal tide observed in MSC, based on $M_{2}$ characteristic ray tracing: "smooth ridge" (A) and "steep ridge" (B).

the sharp (greater than $90^{\circ}$ ) meander of the canyon axis at the mouth of the bay (Fig. 19) without significant dissipation or scattering. The eastward endpoint, or apex of the wedge, is the head of the canyon. The bathymetric profile encountered along the center of the wedge (indicated with a dashed line in Fig. 19) is depicted in Fig. 20. Two prominent bathymetric features along the wedge are the large rise in the sea floor referred to as "smooth ridge" and a steeper feature, which for the purposes of this discussion is dubbed "steep ridge."

The characteristic ray paths emanating shoreward $\left(010^{\circ} \mathrm{T}\right)$ and seaward $\left(260^{\circ} \mathrm{T}\right)$ from these two sites were calculated for ITEX1 and ITEX2 stratification conditions (Fig. 20). The buoyancy frequency profile used for the calculations in water deeper than $400 \mathrm{~m}$ was computed from the average density profile from 50 CTD casts made between November 1989 and December 1992 at $36.64^{\circ} \mathrm{N}, 122.14^{\circ} \mathrm{W}$ (Rosenfeld et al. 1994). For rays propagating in depths shallower than $400 \mathrm{~m}$, the buoyancy frequency profiles calculated from the average density profiles obtained at the ITEX1 and ITEX2 deep CTD stations were used.

The ray traces reveal that along much of the smooth ridge, the bottom slope is near-critical for the $M_{2}$ frequency and thus favorable for internal tide generation. Additionally, the general shape of the smooth ridge is concave downward (convex), which Baines (1974) and Gilbert and Garrett (1989) show to be more favorable for critical frequency energy enhancement and internal tide generation than flat or concave upward slopes. The narrow beam of rays emanating shoreward from the smooth ridge reflects from the sea surface prior to encountering the head of the canyon (backward reflected rays from the canyon head are not depicted). This sur- 

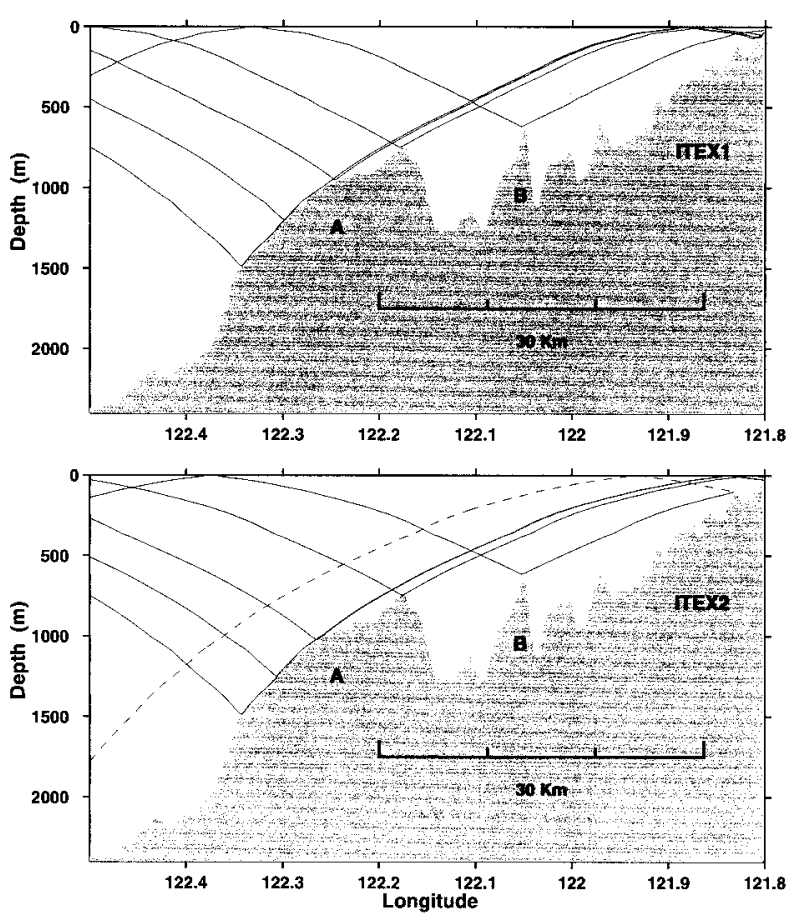

FIG. 20. The $M_{2}$ characteristics calculated from the internal wave dispersion relation (with $f=8.726 \times 10^{-5} \mathrm{~s}^{-1}$ ) showing possible paths of energy propagation from the smooth ridge (A) and the steep ridge (B) into MSC. The dashed line represents a reflected ray.

face reflection would cause near-surface intensification of the currents and might explain the relatively strong tidal currents observed near the head of the canyon with HF radar (Fig. 1) and the higher near-surface values of KE observed in ITEX1 (Fig. 17). The reflection would cause a $180^{\circ}$ phase shift in $w$ and vertical displacement, but the phase of the horizontal currents would be unaffected. The energy propagating eastward from the tip of the steep ridge enters the canyon at greater depth than the energy from the smooth ridge and does not encounter the sea surface until very near the canyon head. In order to keep Fig. 20 uncluttered, rays emanating downward from the tips of the two ridges are not drawn; however, the presence of downward-propagating energy would be expected. Energy propagating eastward and downward from the steep ridge would be expected to reach the floor of MSC somewhere between $122.0^{\circ}-121.9^{\circ} \mathrm{W}$, and could contribute to bottom intensification of the baroclinic tidal currents. Energy propagating downward and eastward from the smooth ridge would encounter the western side of the steep ridge, reflecting backward and farther downward. It would thus not have an effect on currents inside the Bay.

The characteristics calculated with the ITEX2 buoyancy frequency profile are flatter than the ITEX1 characteristics due to increased stratification. The rays from the smooth ridge therefore travel farther before reflecting from the surface, and the ray propagating eastward from the steep ridge encounters a steep bump near $121.83^{\circ} \mathrm{W}$, that is actually a portion of the north wall near the canyon head. The ray path corresponding to the theoretical backward (supercritical) reflection from this feature is depicted with a dashed line. This backward reflection would cause a $180^{\circ}$ phase shift in the $u$ component of velocity. The superposition of shoreward and seaward propagating energy would result in a standing wave, consistent with the ITEX 2 observations. The availability of this backward-reflected energy could explain why the difference in energy densities between the deep and shallow stations in ITEX2 is so much less than in ITEX1.

The ray paths from the smooth and steep ridges are superimposed on the $M_{2} u$ phases observed during ITEX1 and ITEX2 in Fig. 12. Remarkable agreement is seen between the observed isophase lines and the theoretical ray paths. The ITEX1 $u$ phases vary smoothly in $x$ and $z$, with phase lag increasing toward the canyon floor from $-2 \mathrm{~h}$ to $+2 \mathrm{~h}$. The downward phase propagation is consistent with upcanyon energy propagation. The isophase lines clearly lie along characteristics, nearly parallel to the canyon floor. In their analyses of CTD and thermistor chain measurements at several sites seaward of the Bay of Biscay, Pingree and New $(1989,1991)$ documented a linear increase in displacement phase of 2-3 h across a well-defined beam that they observed propagating offshore. Additionally, they observed phase to be constant along the beam.

The ITEX2 phase lags, by contrast, rapidly change from their near-surface values of $\pm 6 \mathrm{~h}\left(\approx 180^{\circ}\right.$ out of phase with sea level) to values between 0 and $+2 \mathrm{~h}$ (nearly in phase with sea level). The depth at which this phase shift occurs changes gradually from approximately $90 \mathrm{~m}$ at the westernmost station to approximately $25 \mathrm{~m}$ at the easternmost station. These are the same depths at which the current ellipses are at minimum strength (Fig. 8). The collocation of these two lines indicates the presence of a node in horizontal velocity, and the ray paths superimposed on the ITEX2 phases show that this node lies along the characteristic calculated from the average ITEX2 density profile. This is further evidence that the internal tide was standing during ITEX2.

Internal seiches in basins have been the subject of recent studies (Maas and Lam 1995; Münnich 1996), but they have rarely been observed in the ocean. Niiler (1968) discusses a seiching internal tide in the Straits of Florida, Winant and Bratkovich (1981) identify internal tides standing in the cross-shelf plane on the narrow southern California shelf, and Griffin and Middleton (1992) discuss standing internal wave patterns in the nearshore region off Sydney, Australia. A common factor in the oceanic observations is the presence of a narrow continental shelf, which implies that little dissipation occurs between the internal tide generation area (most likely the shelf break) and the reflecting boundary (the coast). 


\section{b. Comparison to modal solutions for standing waves}

Wunsch (1968) derived analytic solutions for internal waves over a linear wedge in an inviscid, Boussinesq fluid of constant buoyancy frequency. The resulting standing wave pattern indicates a linear decrease in wavelength and increase in velocity amplitude as the intersection of the bottom and surface is approached. Furthermore, a region of high shear was shown to exist along the floor of the wedge. In view of the few oceanic observations available at the time, and having failed to reproduce the predicted line of high shear in laboratory experiments, Wunsch (1969) considered a subsequent set of propagating solutions as more appropriate for application to the ocean. The ITEX2 observations represent a good opportunity to test Wunsch's earlier standing wave results.

Wunsch introduces the streamfunction $\hat{\psi}$, which describes two-dimensional motion in a stably stratified, Boussinesq fluid such that $u=\hat{\psi}_{z}$ and $w=\hat{\psi}_{x}$. Linear, inviscid, hydrostatic, independent of the alongshore coordinate, and irrotational periodic internal wave motion of radian frequency $\omega\left(\hat{\psi}=\psi e^{-i \omega t}\right)$ is described by

$$
\psi_{z z}-\frac{1}{c^{2}} \psi_{x x}=0, \quad c^{2}=\frac{\omega^{2}}{N^{2}-\omega^{2}} .
$$

Rotational effects can easily be incorporated and are generally important for internal tides, but the irrotational case appears to be more applicable to internal tide propagation in MSC.

In a wedge with bottom depth defined by $z=-\gamma x$, the general solution to (7) is

$$
\psi=F(c x-z)+G(c x+z) .
$$

In polar coordinates, with $x=r \cos \beta, z=r \sin \beta$, $(\beta$ $=\tan ^{-1} \gamma$, the angle of the bottom slope)

$$
\begin{aligned}
\psi= & F\left[r\left(1+c^{2}\right)^{1 / 2} \cos (\beta+\alpha)\right] \\
& +G\left[r\left(1+c^{2}\right)^{1 / 2} \cos (\beta-\alpha)\right], \quad \alpha=\tan ^{-1} \frac{1}{c} .
\end{aligned}
$$

Wunsch then considers the solutions $F=\sin [p \ln (c x-$ $z)], G=-\sin [p \ln (c x+z)]$ which give velocity fields of

$$
\begin{aligned}
u(x, z)= & -\psi_{z}(x, z) \\
= & \frac{p}{c x-z} \cos [p \ln (c x-z)] \\
& +\frac{p}{c x+z} \cos [p \ln (c x+z)] \\
w(x, z)= & -\psi_{x}(x, z) \\
= & \frac{p c}{c x-z} \cos [p \ln (c x-z)] \\
& -\frac{p c}{c x+z} \cos [p \ln (c x+z)],
\end{aligned}
$$

with

$$
p=2 n \pi / \ln \left(\frac{c+\gamma}{c-\gamma}\right),
$$

where $n$ is the mode number. The best match of these velocity fields to the ITEX2 observations was obtained by summing the first two modes with $\gamma=0.035$ (appropriate for the canyon floor) and $N=3.0 \times 10^{-3} \mathrm{~s}^{-1}$ (consistent with the $N$ profile computed from the ITEX2 deep station CTD casts). For comparison to ITEX2 station B2/C3 measurements, a bottom depth of $420 \mathrm{~m}$ was used to determine the appropriate location on the idealized wedge. For a wedge slope of 0.035 , the depth of $420 \mathrm{~m}$ corresponds to a distance from the wedge apex of $x=12 \mathrm{~km}$. The distance from the apex was then decreased by $740 \mathrm{~m}$ (based on the approximate distance between the centers of the geographic bins) for comparison to each subsequent ADCP geographical bin along the canyon axis. The theoretical and observed $u$ and $w$ fields at ITEX2 station B2/C3 are depicted in Fig. 21. The observed $u$ field is given by

$$
u_{M_{2}}=\frac{u_{\text {maj }} \cos \left(G-G_{\text {max }}\right)}{u_{\max }},
$$

where $u_{\text {maj }}$ is the $M_{2}$ semimajor axis length resulting from the harmonic analysis, $u_{\max }$ is the largest $u_{\text {maj }}$ in the water column, and $G_{\max }$ is the Greenwich phase corresponding to the $u_{\max }$ ellipse. The $u$ field therefore shows the distribution of the currents when $u_{\max }$ is at its maximum upcanyon value. The observed $w$ field is similar, with $w$ estimated from $\xi_{o} \omega$ and normalized by $w_{\max }$. Likewise, the theoretical fields are normalized by the maximum $u$ and $w$ values.

The "Wunsch modes" correctly describe the depth of the $u$ and $w$ maxima, as well as the shallowest node in $u$ and the deepest node in $w$. Also depicted in Fig. 21 are the theoretical and observed $u$ fields corresponding to the first and second ADCP bins shoreward of station B2. The observed shoaling of the shallow nodes, and the depths of the current maxima, are well described by the theoretical mode shapes. The constant $N$ assumption for the theoretical modes necessitated choosing higher $N$ values for comparison to the shallower station $u$ fields (not depicted), but no satisfactory fit could be found for the observations closest to the canyon head. The failure of linear theory near the canyon head is anticipated, since the reflection of energy from the narrow walls and the floor is expected to cause complex phase shifts in $u$ and $w$.

The $u$ profiles suggest zones of high shear in the vicinity of the nodes and the sea floor. Although the depths of the theoretical near-bottom nodes and phase reversals in $u$ were beyond the view of the downwardlooking ADCP (or, in the shallower end of the canyon, unmeasurable due to side lobe reflections from the canyon walls), the relatively large amplitudes of the observed baroclinic velocities at middepth imply their existence since the amplitude of the depth-averaged $u$ cur- 


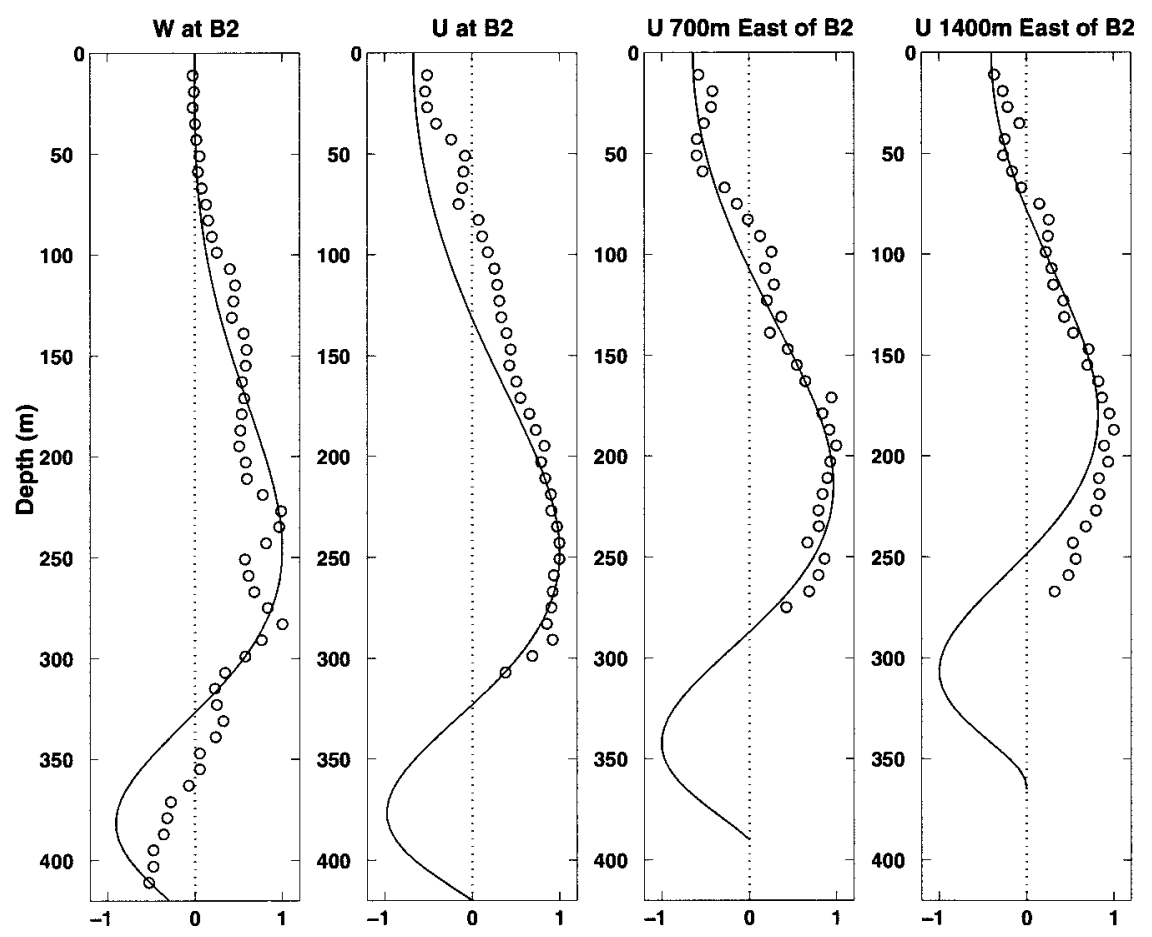

FIG. 21. Observed and theoretical vertical current structure during ITEX2. East-west and vertical (left panel) velocity profiles $(\bigcirc)$, normalized by the maximum value in the profile, compared with theoretical solutions (solid lines) for the sum of the first two standing wave modes of Wunsch (1968). Station locations are shown in Fig. 3. Vertical velocities are inferred from observed isopycnal displacements.

rent is required to be close to the very small barotropic amplitude. In order to estimate the amplitude of the nearbottom $M_{2}$ currents in MSC, the hourly $u$ and $v$ velocities from the three cross-canyon geographic bins located over the deeper portions of the canyon (those that were collocated with CTD stations $\mathrm{C} 2, \mathrm{C} 3$, and C4) were averaged over depth, and the depth-averaged values were then rotated $10^{\circ}$ counterclockwise into along- and cross-canyon components. The amplitude of the depthaveraged, along-canyon $\mathrm{M}_{2}$ current flowing across the $5.49 \times 10^{5} \mathrm{~m}^{2}$ cross-sectional area of these three geographic bins was approximately $6 \mathrm{~cm} \mathrm{~s}^{-1}$, with maximum shoreward flow occurring approximately $1 \mathrm{~h}$ before high tide. The area of that portion of the water column not measured by the ADCP in these three geographic bins was roughly $1.3 \times 10^{5} \mathrm{~m}^{2}$, including 1.4 $\times 10^{4} \mathrm{~m}^{2}$ in the top $7 \mathrm{~m}$ of the water column. In order to obtain a depth-averaged velocity of zero (since the barotropic $u$ amplitude of $0.58 \mathrm{~cm} \mathrm{~s}^{-1}$ is essentially zero, to the accuracy of the ADCP measurements), the amplitude of the $M_{2}$ currents in the unmeasured portion of the water column must be equal to $24.8 \mathrm{~cm} \mathrm{~s}^{-1}$, with maximum downcanyon flow occurring approximately 1 $\mathrm{h}$ before high tide.

The average amplitude of the $M_{2}$ currents in the top ADCP bin (7-15 $\mathrm{m}$ ) at the three midcanyon ADCP stations is $11 \mathrm{~cm} \mathrm{~s}^{-1}$, and the maximum downcanyon flow does in fact occur approximately $1 \mathrm{~h}$ prior to high tide.
An estimate of $26.5 \mathrm{~cm} \mathrm{~s}^{-1}$ for the amplitude of the near-bottom currents alone is arrived at by assuming that the $M_{2}$ currents in the top ADCP bin are also representative of the flow in the top $7 \mathrm{~m}$ and subtracting that portion of the unmeasured flow. The magnitude of this estimated current velocity is reasonable, based on the observations of Shepard et al. (1976) and on the S4 mooring observations presented in this study, although it cannot be determined whether the internal tide existed in the form of a standing wave during the periods of those observations.

\section{Conclusions}

Barotropic semidiurnal tidal currents, associated with the essentially co-oscillating sea level in Monterey Bay, are estimated to be less than $1 \mathrm{~cm} \mathrm{~s}^{-1}$. During April (ITEX1) and October (ITEX2) 1994, a shipboard ADCP measured tidal currents in excess of $20 \mathrm{~cm} \mathrm{~s}^{-1}$ approximately $150 \mathrm{~m}$ above the floor of Monterey Canyon, along the canyon axis. In a layer 150-250 m thick surrounding the current maxima, $M_{2}$ current amplitudes were typically $15-20 \mathrm{~cm} \mathrm{~s}^{-1}$. The along-canyon component of velocity was found to be much stronger than the cross-canyon component, and most of the alongcanyon velocity variance is accounted for by the semidiurnal internal tide. Topographic steering by the canyon walls, which results in highly rectilinear current ellipses, 
also enhances the potential energy relative to the kinetic energy.

The along-canyon phase differences between isopycnal oscillations at a given depth during ITEX1 suggest an internal tide horizontal wavelength of approximately $30 \mathrm{~km}$. A similar wavelength is evident in the highresolution, along-canyon XBT survey conducted during ITEX1 (Fig. 10). This horizontal wavelength is greater than the more typical value of $20 \mathrm{~km}$ observed over continental shelves (Rosenfeld 1990) but less than the 42-km wavelength computed by Petrie (1975) for the internal tide over the Scotian slope.

We were also able to calculate the orientation in the vertical/along-canyon plane of the wavevector and the group velocity. The energy in the internal tide is concentrated in a beam nearly parallel to the canyon floor at an angle of approximately $2.3^{\circ}$ to the horizontal. The orientation of the $M_{2}$ characteristic (the path along which internal tide energy propagates) was calculated from (i) the dispersion relation for internal waves, (ii) the ratio of horizontal to vertical wavevector components, (iii) the ratio of vertical to east-west (along-canyon) velocity components, (iv) the alignment of isophase lines for semidiurnal isopycnal and along-canyon velocity oscillations, (v) the alignment of kinetic and potential energy maxima, and (vi) the alignment of $180^{\circ}$ phase shifts in the along-canyon velocity component with the location of velocity minima (nodes) in the case of the standing wave pattern in ITEX2. In ITEX1, the signs of the wavevector components $(k>0$ and $m<$ 0 ), and the phase relationships between the semidiurnal isopycnal oscillations and along-canyon current oscillations, indicate that phase propagation is eastward and downward. This implies that the direction of energy propagation along the characteristics is eastward and upward. The magnitude of the group velocity, based on the measured wavenumber and buoyancy frequency, is estimated to be $50-55 \mathrm{~cm} \mathrm{~s}^{-1}$. This represents an upper bound on the current speeds associated with the internal tide in MSC, except perhaps in turbulent bores as the internal waves break down at the canyon head.

The vertical profiles of both along-canyon and vertical (inferred from the isopycnal displacements) velocity components during ITEX2 are well-described by modal solutions (Wunsch 1968) for a standing wave over a sloping bottom (Fig. 21). In the lower portion of the water column not measured by the VM-ADCP, the modal solutions suggest another $180^{\circ}$ phase shift in the along-canyon velocity component, with a node located approximately $100 \mathrm{~m}$ above bottom. A near-bottom $180^{\circ}$ phase shift in the vertical component of velocity, predicted by the Wunsch modes, was observed. Projecting the observed currents to the bottom using the modal solutions for ITEX2, predicts bulk shears of the horizontal velocity near the bottom of approximately $4 \times$ $10^{-3} \mathrm{~s}^{-1}$, decreasing from $20 \mathrm{~cm} \mathrm{~s}^{-1} 45 \mathrm{~m}$ above the bottom to $0 \mathrm{~cm} \mathrm{~s}^{-1}$ at the bottom.

During ITEX1, the phase relationship between sea level and current indicates that the highest shoreward velocities in the beam in the lower part of the water column occur 2-3 h after high tide (Fig. 12). During ITEX2, maximum shoreward flow throughout the middle of the water column occurs $1-2 \mathrm{~h}$ before high tide, while near the surface, maximum shoreward flow is weaker than at middepth and occurs close to the time of low tide (Fig. 8 and 12).

Although the ITEX records are short, there is some evidence to suggest that there is phase-locking between the surface and internal tide. Higher energy levels were observed during the spring tide conditions of ITEX1, versus the neap tide conditions of ITEX2. Further evidence for this phase-locking is provided by the springneap cycle in the late spring month-long record of nearbottom current and temperature obtained $5 \mathrm{~km}$ from the canyon head in 1991. In that record, the relative proportions of the $M_{2}, S_{2}$, and $N_{2}$ semimajor axis lengths and perturbation temperature amplitudes are nearly the same as for sea level perturbation amplitudes.

While phase-locking between the internal and surface tides is rare on the continental shelf, due to the inherent variability of stratification and mean flow in the vicinity of the shelf break generation site (Sandstrom 1991), it has been observed in deeper regions such as the Rockall Trough north of Ireland (Sherwin 1988) and over the continental slope off northern California (Noble et al. 1987). Since it appears that the internal tide propagating shoreward in MSC is generated at a depth greater than $500 \mathrm{~m}$, where temporal variations in the density field are small, it is not surprising that the primary factor in the variability of the internal tide would be the springneap cycle in the barotropic forcing.

Two offshore locations are identified as likely generation sites for the internal tides propagating in MSC (Fig. 19). The larger topographic feature, the smooth ridge, lies approximately $35 \mathrm{~km}$ due west of the canyon head. The smaller, steeper topographic feature, the steep ridge, lies approximately $20 \mathrm{~km}$ from the canyon head, at the mouth of the bay. The $M_{2}$ ray traces demonstrate the potential for semidiurnal internal tidal energy to propagate shoreward into MSC from these two ridges along characteristics that are nearly parallel to the canyon floor (Fig. 20).

Energy density values in the $1000-2400 \mathrm{~J} \mathrm{~m}^{-2}$ range were measured, with nearly equal partitioning between kinetic and potential energy. This KE to PE ratio is less than half that expected for a freely propagating internal wave of semidiurnal period at this latitude, and is probably the result of topographic constraints. During ITEX1, the difference in energy flux between the deep and shallow CTD stations, 1286 and $806 \mathrm{~W} \mathrm{~m}^{-1}$ respectively, yields a conservative dissipation estimate of $1.3 \times 10^{-4} \mathrm{~W} \mathrm{~m}^{-3}$. Disspation rates an order of magnitude greater are expected when narrowing of the canyon is taken into account.

Temporal variations in stratification do play a role in determining the fate of the internal tide within the inner 
reaches of the canyon. The standing wave pattern observed during ITEX2 indicates the superposition of shoreward and seaward propagating energy. The presence of this reflected energy in ITEX2, and its apparent absence in ITEX1, can be attributed to increased stratification during ITEX2 and hence, flatter ray paths that cause a greater percentage of the energy to encounter, and be reflected by, the canyon walls and head. Reflection of rays from the sea surface in this region may explain the near-surface kinetic energy maxima observed there during ITEX1. Presumably, the internal tide energy is then dissipated closer to the head and/or along the canyon rim.

Evidence for dissipation, or energy flux divergence, along the rim of the canyon comes from observations of enhanced isopycnal displacements and cross-canyon orientation of tidal ellipses over the southern rim during ITEX2. The internal tides generated at the southern rim, at a location several kilometers farther seaward than previous internal tide measurements, suggests that previous estimates of the amount of water transported out of the canyon due to the "tidal pumping" of denser water onto the shelf (Broenkow and McKain 1972; Shea and Broenkow 1982; Heard 1992) may be conservative. The relative lack of internal tide energy over the northern rim may be due to local bathymetric effects and/or rotational effects.

In conclusion, these observations show energetic coastal tidal currents in a submarine canyon with a bottom slope nearly critical for internal waves of semidiurnal frequency. These internal waves result in tidalperiod pumping of denser water from the canyon onto the adjacent continental shelf. They may also be responsible for enhanced mixing. Petruncio (1996) uses numerical simulations to shed light on how the strength and structure of the internal tide depends on canyon size and shape and seasonal variations in stratification. It is hoped that the model results will enable the lessons learned from Monterey Bay to be applied to other parts of the continental margins.

Acknowledgments. The authors would like to thank Dr. Curtis Collins and the crew of the R/V Pt. Sur for their assistance with data collection, and Tarry Rago, Paul Jessen, and Mike Cook for their help with data processing as well as collection. Ship time for both cruises was sponsored by the Oceanographer of the Navy, via the Naval Meteorology and Oceanography Command, in support of graduate education at NPS. We thank MBARI for providing the ADCP data used in Fig. 1. Dr. Petruncio was supported by an Office of Naval Research Graduate Fellowship during his graduate studies, and Dr. Rosenfeld was supported by MBARI during much of the time she worked on this project. Support from ONR Contracts N0001495WR30022 (Paduan), N000149310403 (Rosenfeld), and N0001497WR30009 (Paduan and Rosenfeld) is also gratefully acknowledged.

\section{REFERENCES}

Baines, P. G., 1974: The generation of internal tides over steep continental slopes. Philos. Trans. Roy. Soc. London, 277, 27-58.

, 1986: Internal tides, internal waves, and near-inertial motions. Baroclinic Processes on Continental Shelves, C. N. K. Mooers, Ed., Amer. Geophys. Union, 19-31.

Barbee, W. B., J. G. Dworski, J. D. Irish, L. H. Larsen, and J. M. Rattray, 1975: Measurements of internal waves of tidal frequency near a continental boundary. J. Geophys. Res., 80, 19651974.

Battisti, D. S., and A. J. Clarke, 1982: A simple method for estimating barotropic tidal currents on continental margins with specific application to the $M_{2}$ tide off the Atlantic and Pacific coasts of the United States. J. Phys. Oceanogr., 12, 8-16.

Breaker, L. C., and W. W. Broenkow, 1994: The circulation of Monterey Bay and related processes. Oceanography and Marine Biology: An Annual Review, Vol. 32, A. D. Ansell, R. N. Gibson, and M. Barnes, Eds., UCL Press, 1-64.

Brink, K. H., 1988: On the effect of bottom friction on internal waves. Contin. Shelf Res., 8, 397-403.

Broenkow, W. W., and S. J. McKain, 1972: Tidal oscillations at the head of Monterey Submarine Canyon and their relation to oceanographic sampling and the circulation of water in Monterey Bay. Moss Landing Marine Laboratories Tech. Pub. 72-05, 42 pp. [Available from Moss Landing Marine Laboratories, P.O. Box 450, Moss Landing, CA 95039.]

Cacchione, D., and C. Wunsch, 1974: Experimental study of internal waves over a slope. J. Fluid Mech., 66, 223-239.

Caster, W. A., 1969: Near-bottom currents in Monterey Submarine Canyon and on the adjacent shelf. M.S. thesis, Dept. of Oceanography, Naval Postgraduate School, 203 pp. [Available from Naval Postgraduate School, Monterey, CA 93943-5000.]

Coelho, E. F., 1994: Tidal dynamics and mixing over steep topography. Ph.D. dissertation, Dept. of Oceanography, Naval Postgraduate School, 213 pp. [Available from Naval Postgraduate School, Monterey, CA 93943-5000.]

DeWitt, L. M., M. D. Levine, C. A. Paulson, and W. V. Burt, 1986: Semidiurnal internal tide in JASIN: Observations and simulation. J. Geophys. Res., 91, 2581-2592.

Dooley, J. J., 1968: An investigation of near-bottom currents in the Monterey Submarine Canyon. M.S. thesis, Dept. of Oceanography, Naval Postgraduate School, 58 pp. [Available from Naval Postgraduate School, Monterey, CA 93943-5000.]

Drakopolous, P., and R. F. Marsden, 1993: The internal tide off the west coast of Vancouver Island. J. Phys. Oceanogr., 23, 758775.

Eriksen, C. C., 1982: Observations of internal wave reflection off sloping bottoms. J. Geophys. Res., 87, 525-538.

- 1985: Implications of ocean bottom reflection for internal wave spectra and mixing. J. Phys. Oceanogr., 15, 1145-1156.

Filloux, J. H., and R. L. Snyder, 1979: A study of tides, setup, and bottom friction in a shallow semi-enclosed basin. Part I: Field experiment and harmonic analysis. J. Phys. Oceanogr., 9, 158169.

Foreman, M. G. G., 1977: Manual for tidal heights analysis and prediction. Institute of Ocean Sciences, Patricia Bay Pacific Mar. Sci. Rep. 77-10, Institute of Ocean Sciences, Patricia Bay, Victoria, British Columbia, Canada, $97 \mathrm{pp}$.

— 1978: Manual for tidal currents analysis and prediction. Institute Of Ocean Sciences, Patricia Bay Pacific Mar. Sci. Rep. 78-6, Institute of Ocean Sciences, Patricia Bay, Victoria, British Columbia, Canada, 70 pp.

_ 1995: Tide removal requiring a dynamical interpretation. Quantitative Skill Assessment for Coastal Ocean Models, D. R. Lynch and A. M. Davies, Eds., Amer. Geophys. Union, 224-239.

Gardner, W. D., 1989: Periodic resuspension in Baltimore Canyon by focusing of internal waves. J. Geophys. Res., 94, 18 185-18 194.

Garrett, C., and W. Munk, 1975: Space-time scales of internal waves: A progress report. J. Geophys. Res., 80, 291-297. 
and - 1979: Internal waves in the ocean. Annu. Rev. Fluid Mech., 11, 339-369.

- , and D. Gilbert, 1988: Estimates of vertical mixing by internal waves reflected off a sloping bottom. Small-Scale Turbulence and Mixing in the Ocean, J. C. J. Nihoul and B. M. Jamart, Eds., Elsevier, 405-423.

Gatje, P. H. and D. D. Pizinger, 1965: Bottom current measurements in the head of Monterey Submarine Canyon. M.S. thesis, Dept. of Oceanography, Naval Postgraduate School, 61 pp. [Available from Naval Postgraduate School, Monterey, CA 93943-5000.]

Gilbert, D., 1993: A search for evidence of critical internal wave reflection on the continental rise and slope off Nova Scotia. Atmos.-Ocean, 31, 99-122.

— , and C. Garrett, 1989: Implications for ocean mixing of internal wave scattering off irregular topography. J. Phys. Oceanogr., 19, $1716-1729$.

Gill, A. E., 1982: Atmosphere-Ocean Dynamics. Academic Press, $662 \mathrm{pp}$.

Godin, G., 1972: The Analysis of Tides. University of Toronto Press, $264 \mathrm{pp}$.

— 1991: The analysis of tides and currents. Tidal Hydrodynamics, B. B. Parker, Ed., John Wiley and Sons, 675-709.

Gordon, R. L. and N. F. Marshall, 1976: Submarine canyons: Internal wave traps? Geophys. Res. Lett., 3, 622-624.

Griffin, D. A., and J. H. Middleton, 1992: Upwelling and internal tides over the inner New South Wales continental shelf. J. Geophys. Res., 97, 14 389-14 405.

Heard, J. A., 1992: A kinematic model of baroclinic tidal currents at the head of Monterey Submarine Canyon. M.S. thesis, Moss Landing Marine Laboratories, San Jose State University, 59 pp. [Available from Moss Landing Marine Laboratories, P.O. Box 450, Moss Landing, CA 95039.]

Hickey, B. M., 1995: Coastal submarine canyons. Proc. 'Aha Huliko'a, Hawaiian Winter Workshop, Topographic Effects in the Ocean, Honolulu, HI, School of Ocean and Earth Science and Technology, University of Hawaii at Manoa, 95-110.

Hollister, J. E., 1975: Currents in Monterey Submarine Canyon. M.S. thesis, Dept. of Oceanography, Naval Postgraduate School, 86 pp. [Available from Naval Postgraduate School, Monterey, CA 93943-5000.]

Holloway, P. E., 1984: On the semidiurnal internal tide at a shelfbreak region on the Australian North West Shelf. J. Phys. Oceanogr., 14, 1787-1799.

_ 1991: On dissipation of internal tides. Tidal Hydrodynamics, B. B. Parker, Ed., John Wiley and Sons, 449-468.

Hotchkiss, F. S., and C. H. Wunsch, 1982: Internal waves in Hudson Canyon with possible geological implications. Deep-Sea Res., 29, 415-442.

Hunkins, K., 1988: Mean and tidal currents in Baltimore Canyon. $J$. Geophys. Res., 93, 6917-6929.

Huthnance, J. M., 1989: Internal tides and waves near the continental shelf edge. Geophys. Astrophys. Fluid Dyn., 48, 81-106.

— 1995: Circulation, exchange, and mixing at the ocean-shelf boundary. Proc. 'Aha Huliko'a, Hawaiian Winter Workshop, Topographic Effects in the Ocean, Honolulu, HI School of Ocean and Earth Science and Technology, University of Hawaii at Manoa, 85-93.

- and P. G. Baines, 1982: Tidal currents in the northwest African upwelling region. Deep-Sea Res., 29, 285-306.

Ivey, G. N., and R. I. Nokes, 1989: Vertical mixing due to the breaking of critical internal waves on sloping boundaries. J. Fluid Mech., 204, 479-500.

Joyce, T. M., 1989: On in situ "calibration" of shipboard ADCPs. J. Atmos. Oceanic Technol., 6, 169-172.

Konyaev, K. V., K. D. Sabinin, and A. N. Serebryany, 1995: Largeamplitude internal waves at the Mascarene Ridge in the Indian Ocean. Deep-Sea Res., 42, 2075-2091.

Largier, J. L., 1994: The internal tide over the shelf inshore of Cape Point Valley, South Africa. J. Geophys. Res., 99, 10 023-10 034.

Lazanoff, S. M., 1971: An evaluation of a numerical water elevation and tidal current prediction model applied to Monterey Bay. M.S. thesis, Dept. of Oceanography, Naval Postgraduate School, 148 pp. [Available from Naval Postgraduate School, Monterey, CA 93943-5000.]

Lentz, S. J., 1993: The accuracy of tide-gauge measurements at subtidal frequencies. J. Atmos. Oceanic Technol., 10, 238-245.

Maas, L. R. M., and F. A. Lam, 1995: Geometric focusing of internal waves. J. Fluid Mech., 300, 1-41.

McKay, D. A., 1970: A determination of surface currents in the vicinity of the Monterey Submarine Canyon by the electromagnetic method. M.S. thesis, Dept. of Oceanography, Naval Postgraduate School, 74 pp. [Available from Naval Postgraduate School, Monterey, CA 93943-5000.]

Miles, J. W., 1972: Kelvin waves on oceanic boundaries. J. Fluid Mech., 55, 113-127.

Munk, W., F. Snodgrass, and M. Wimbush, 1970: Tides offshore: Transition from California coastal to deep-sea waters. Geophys. Fluid Dyn., 1, 161-235.

Münnich, M., 1996: The influence of bottom topography on internal seiches in stratified media. Dyn. Atmos. Oceans, 23, 257-266.

Niiler, P. P., 1968: On the internal tidal motions in the Florida Straits. Deep-Sea Res., 15, 113-123.

Njus, I. J., 1968: An investigation of the environmental factors affecting the near-bottom currents in Monterey Submarine Canyon. M.S. thesis, Dept. of Oceanography, Naval Postgraduate School, 80 pp. [Available from Naval Postgraduate School, Monterey, CA 93943-5000.]

Noble, M., L. K. Rosenfeld, R. L. Smith, J. V. Gardner, and R. C. Beardsley, 1987: Tidal currents seaward of the northern California continental shelf. J. Geophys. Res., 92, 1733-1744.

Paduan, J. D., D. E. Barrick, B. J. Lipa, and E. T. Petruncio, 1995: Surface currents within and offshore of Monterey Bay as mapped by a multiple-site HF Radar (CODAR) network. Proc. Fifth Working Conference on Current Measurement, St. Petersburg, FL, IEEE, 137-142.

Park, Y., 1986: Semidiurnal internal tides on the continental shelf off Abidjan. J. Phys. Oceanogr., 16, 1585-1592.

Petrie, B., 1975: $M_{2}$ surface and internal tides on the Scotian shelf and slope. J. Mar. Res., 33, 303-323.

Petruncio, E. T., 1993: Characterization of tidal currents in Monterey Bay from remote and in-situ measurements. M.S. thesis, Dept. of Oceanography, Naval Postgraduate School, 113 pp. [Available from Naval Postgraduate School, Monterey, CA 93943-5000.]

_ 1996: Observations and modeling of the internal tide in a submarine canyon. Ph.D. dissertation, Dept. of Oceanography, Naval Postgraduate School, 181 pp. [Available from Naval Postgraduate School, Monterey, CA 93943-5000.]

Pingree, R. D., and A. L. New, 1989: Downward propagation of internal tidal energy into the Bay of Biscay. Deep-Sea Res., 36, 735-758.

- , and -1991 : Abyssal penetration and bottom reflection of internal tidal energy in the Bay of Biscay. J. Phys. Oceanogr., 21, 28-39.

Prandle, D., 1982: The vertical structure of tidal currents. Geophys. Astrophys. Fluid Dyn., 22, 29-49.

Prinsenberg, S. J., and J. M. Rattray, 1975: Effects of continental slope and variable Brünt-Väisälä frequency on the coastal generation of internal tides. Deep-Sea Res., 22, 251-263.

_ - W. L. Wilmot and J. M. Rattray, 1974: Generation and dissipation of coastal internal tides. Deep-Sea Res., 21, 263-281.

Regal, R., and C. Wunsch, 1973: $\mathrm{M}_{2}$ tidal currents in the western North Atlantic. Deep-Sea Res., 20, 493-502.

Rosenfeld, L. K., 1990: Baroclinic semidiurnal tidal currents over the continental shelf off Northern California. J. Geophys. Res., 95, 22 153-22 172.

- , and R. C. Beardsley, 1987: Barotropic semidiurnal tidal currents off northern California during the Coastal Ocean Dynamics Experiment (CODE). J. Geophys. Res., 92, 1721-1732.

- R. E. Schramm, J. B. Paduan, J. G. A. Hatcher, and T. Anderson, 1994: Hydrographic data collected in Monterey Bay during 1 
September 1988 to 16 December 1992. Monterey Bay Aquarium Research Institute Tech. Rep. 94-15, 549 pp.

_ T. Anderson, G. Hatcher, J. Roughgarden and Y. Shkedy, 1995: Upwelling fronts and barnacle recruitment in central California. Monterey Bay Aquarium Research Institute Tech. Rep. 95-19, $102 \mathrm{pp}$.

Sandstrom, H., 1991: The origin of internal tides (a revisit). Tidal Hydrodynamics, B. B. Parker, Ed., John Wiley and Sons, Inc., 437-447.

Shea, R. E., and W. W. Broenkow, 1982: The role of internal tides in the nutrient enrichment of Monterey Bay, California. Estuarine Coastal Shelf Sci., 15, 57-66.

Shepard, F. P., N. F. Marshall, P. A. McLoughlin, and G. G. Sullivan, 1979: Currents in Submarine Canyons and Other Sea Valleys. AAPG Studies in Geology No. 8, American Assoc. of Petroleum Geologists, 173 pp.

Sherwin, T. J., 1988: Analysis of an internal tide observed on the Malin Shelf, north of Ireland. J. Phys. Oceanogr., 18, 1035 1054.

Shih, H. H., and L. Baer, 1991: Some errors in tide measurement caused by the dynamic environment. Tidal Hydrodynamics, B. B. Parker, Ed., John Wiley and Sons, 641-671.

Slinn, D. N., and J. J. Riley, 1996: Turbulent mixing in the oceanic boundary layer caused by internal wave reflection from sloping terrain. Dyn. Atmos. Oceans, 24, 51-62.

Tee, K.-T., 1982: The structure of three-dimensional tide-generating currents: Experimental verification of a theoretical model. Estuarine Coastal Shelf Sci., 14, 27-48.

Tisch, T. D., 1990: Seasonal variability of the geostrophic velocity and water mass structure off Point Sur, California,. M.S. thesis, Dept. of Oceanography, Naval Postgraduate School, 135 pp. [Available from Naval Postgraduate School, Monterey, CA 93943-5000.]

Torgrimson, G. M., and B. M. Hickey, 1979: Barotropic and baroclinic tides over the continental slope and shelf off Oregon. $J$. Phys. Oceanogr., 9, 945-961.

Werner, F. E., 1992: Tidal hydrodyamics, quantitative aspects. Encyclopedia of Earth System Science, Vol. 4, Academic Press, 351-367.

White, M., 1994: Tidal and subtidal variability in the sloping benthic boundary layer. J. Geophys. Res., 99, 7851-7864.

Winant, C. D., and A. W. Bratkovich, 1981: Temperature and currents on the southern California shelf: A description of the variability. J. Phys. Oceanogr., 11, 71-86.

Wunsch, C. H., 1968: On the propagation of internal waves up a slope. Deep-Sea Res., 15, 251-258.

, 1969: Progressive internal waves on slopes. J. Fluid Mech., 35, 131-144.

- 1975: Internal tides in the ocean. Rev. Geophys. Space Phys., 13, $167-182$.

- and S. Webb, 1979: The climatology of deep ocean internal waves. J. Phys. Oceanogr., 9, 235-243. 